\title{
WestVirginiaUniversity
}

THE RESEARCH REPOSITORY @ WVU

Graduate Theses, Dissertations, and Problem Reports

2002

\section{Impulsivity and friends who smoke as predictors of adolescent smoking}

Brady Reynolds

West Virginia University

Follow this and additional works at: https://researchrepository.wvu.edu/etd

\section{Recommended Citation}

Reynolds, Brady, "Impulsivity and friends who smoke as predictors of adolescent smoking" (2002). Graduate Theses, Dissertations, and Problem Reports. 1688.

https://researchrepository.wvu.edu/etd/1688

This Dissertation is protected by copyright and/or related rights. It has been brought to you by the The Research Repository @ WVU with permission from the rights-holder(s). You are free to use this Dissertation in any way that is permitted by the copyright and related rights legislation that applies to your use. For other uses you must obtain permission from the rights-holder(s) directly, unless additional rights are indicated by a Creative Commons license in the record and/ or on the work itself. This Dissertation has been accepted for inclusion in WVU Graduate Theses, Dissertations, and Problem Reports collection by an authorized administrator of The Research Repository @ WVU.

For more information, please contact researchrepository@mail.wvu.edu. 


\title{
IMPULSIVITY AND FRIENDS WHO SMOKE AS PREDICTORS OF ADOLESCENT SMOKING
}

\author{
Brady Reynolds \\ Dissertation submitted to the College of Arts and Sciences \\ at West Virginia University \\ in partial fulfillment of the requirements \\ for the degree of
}

Doctor of Philosophy

in

Psychology

Approved by

Katherine Karraker, Ph.D. , Committee Chairperson

Jerry B. Richards, Ph.D.

Kimberly Horn, Ed.D.

Kennon Lattal, Ph.D.

JoNell Strough, Ph.D.

Department of Psychology

Morgantown, West Virginia

2002

Keywords: Impulsivity, Peer Smoking, Adolescence, Adolescent Smoking, Stages

Copyright 2002 Brady Reynolds 


\title{
Abstract \\ Impulsivity And Friends Who Smoke As Predictors Of Adolescent Smoking
}

\author{
Brady Reynolds
}

The present study sought to examine relations between different stages of adolescent cigarette smoking and the variables of impulsivity (delay and probability discounting) and peer friend smoking behavior. Participants were 75 adolescents (40 females) between 14 and 16 years of age. Participants were categorized according to the following patterns of smoking behavior: "never smokers" ( $\mathrm{n}=19$; 10 females) were those who had not tried even one cigarette; "triers" ( $\mathrm{n}=17$; 9 females) were those who had recently tried cigarettes $(\mathrm{M}=3.76$ cigarettes) for the first time; "past experimenters" ( $\mathrm{n}=20 ; 12$ females) were those who had tried cigarettes $(\mathrm{M}=$ 3.75 cigarettes) in the past but had not smoked any in the six months prior to data collection; and "current smokers" ( $\mathrm{n}=19$; 9 females) were those who had smoked every week $(\mathrm{M}=$ 46.42 cigarettes per week) for the six months prior to data collection. It was hypothesized that the current smoker group would be more impulsive than the never smoker and past experimenter groups, which would match similar research done with adult smokers. Also, it was hypothesized that peer friend smoking behavior would match participant smoking behavior, so that participants who were smoking at the time of data collection (current smokers and triers) would report having more friends who smoke than those participants who were not smoking (never smokers and past experimenters). Results revealed that the trier group was significantly more impulsive than the never smoker group. There were no other significant group differences in impulsivity. Also, current smokers reported having more friends who smoked than did past experimenters and never smokers. Inversely, never smokers reported having fewer friends who smoked than triers and current smokers. However, participants from the trier and past experimenter groups did not differ in number of friends who smoked. The results suggest that impulsivity may be related more to adolescents trying cigarettes than to their becoming regular smokers. Also, peer friend smoking appears to be more related to established patterns of smoking or nonsmoking than to initially trying cigarettes. From these findings, suggestions are made for both preventive and cessation types of adolescent smoking intervention programs. 


\section{DEDICATION}

The author wishes to dedicate this work to the memory of his brother, Forrest Lee Reynolds 


\section{ACKNOWLEDGMENTS}

The author wishes to thank all of the committee members for their thoughtful contributions to this project. The author also wishes to offer a special thanks to Cheryl Conaway for her contributions in participant recruitment and in the more general execution of this study. The author would also like to thank Ryan Schiffbauer and Lisa Swenson for their extensive help in data collection. 


\section{TABLE OF CONTENTS}

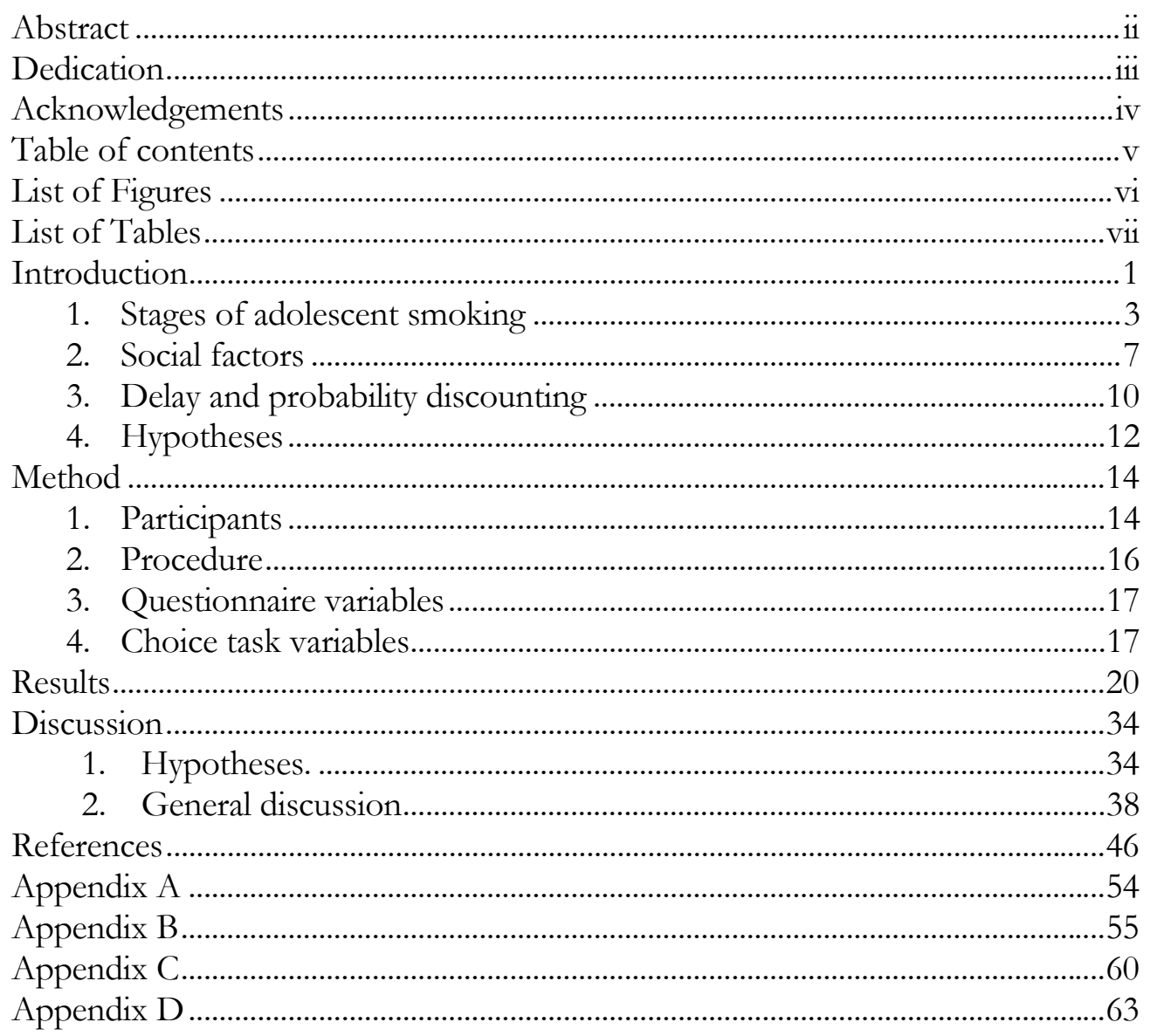




\section{LIST OF FIGURES}

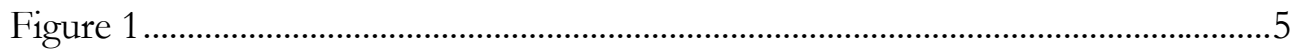

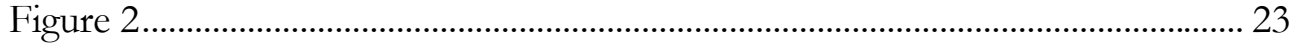

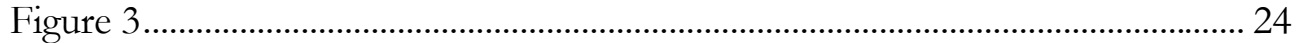




\section{LIST OF TABLES}

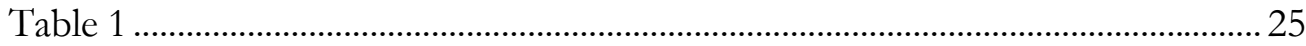

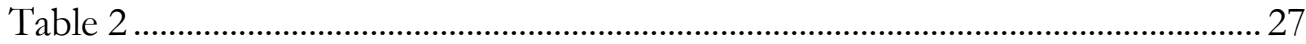

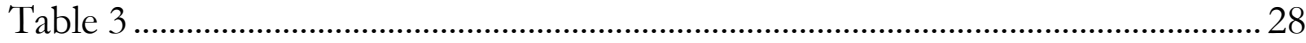

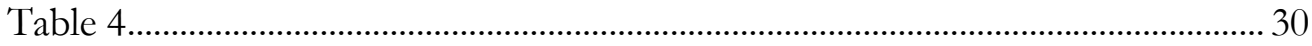

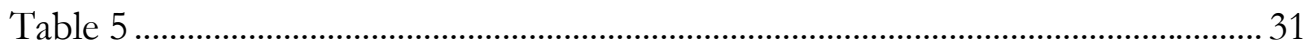

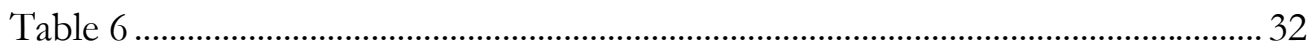

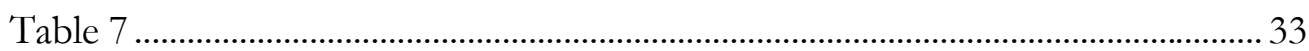




\section{Introduction}

Use of tobacco products is estimated to be responsible for one out of every six deaths in the United States (McMahon, Jason, \& Salina, 1994). One fourth of all adults smoke, resulting in at least 434,000 deaths annually (McMahon et al.). Research has shown that almost all adults who smoke started smoking during adolescence (e.g., Fiore, 1992), and it has recently been estimated that approximately 3000 adolescents start smoking in the United States each day (Glynn, Anderson, \& Schwartz, 1991 as cited by Tompkins, Dino, Zedosky, Harman, \& Shaler, 1999). Such statistics have led to an extensive research effort to identify factors that may predict or lead to the onset of adolescent smoking (Engels, Knibbe, de Vries, \& Drop, 1998).

For the present study, a "personality/social factor” approach (e.g., Mischel, 1999; Reynolds \& Karraker, in press) was adopted for studying different stages of adolescent smoking. In adopting such an approach, both personality and social factors were examined as predictors of different stages of adolescent smoking behavior. In past research, many social variables have been studied in relation to adolescent smoking, among which have been parental smoking (e.g., Flay et al., 1994), quality of an adolescent's attachment to parents (e.g., Krohn, Massey, Skinner, \& Lauer, 1983), socio-economic status (West, Sweeting, \& Ecob, 1999), and number of friends who smoke (e.g., West, Sweeting, \& Ecob, 1999). Of these predictors, number of friends who smoke is often the social variable most predictive of adolescent smoking (e.g., Chassin, Presson, \& Sherman, 1984; Ershler, Leventhal, Fleming, \& Glynn, 1989; Rose, Chassin, \& Sherman, 1996). However, number of friends who smoke is an inconsistent predictor of the frequency or amount of adolescent smoking, with number of friends who smoke being predictive of some patterns of smoking and not other patterns of smoking (e.g., Ary \& Biglan, 1988). The number of friends an adolescent has who smokes was examined in the current study in relation to different patterns of adolescent smoking, which is described in more detail later. 
Also included in the present study as social factors that may relate to adolescent smoking were the smoking behavior of an adolescent's best friends, the smoking behavior of the adolescent's parents, and the adolescent's parents level of education.

By contrast, fewer personality variables have been reported as predictors of adolescent smoking. Some personality research with adolescents has established predictive relations between paper and pencil measures of extroversion, neuroticism, and depression and cigarette smoking (e.g., Cherry \& Kiernan, 1976; Sieber \& Angst, 1990). Also, relations have been found between high sensation seeking and cigarette smoking (Zuckerman, Ball, \& Black, 1990). To summarize the relations between paper and pencil measures of personality and cigarette smoking, Ashton and Stepney (1982) noted that smokers are typically high in risk taking, highly impulsive, and high in sensation seeking. Similarly, Forgays (1986) summarized the personality research on smoking by characterizing smokers as high on extroversion, at least moderately neurotic, highly impulsive, and high in risk taking. However, no personality research to date has considered measures of delay discounting (DD) or probability discounting (PD) as predictors of adolescent smoking. As will be described in more detail later, DD is a measure of impulsivity and is the extent to which an individual discounts the value of a reward (e.g., money, food, weight loss, etc.) as a function of a delay to it being acquired. The more an individual discounts, the more he or she is considered to be impulsive. Similarly, PD represents impulsivity in the discounting of value of a reward as a function of it being probabilistic (i.e., might or might not actually receive the reward). Studies of adults have found that measures of DD and PD are correlated with each other, but they also report that there is little correlation between these measures adults, those who smoke cigarettes discount money by delay significantly more on average than those who have never smoked or those who have quit smoking (Bickel, Odum, \& Madden, 1999). However, even with the correlation between DD and PD, the relation between PD and smoking in adults is less 
clear, with PD not differentiating between smokers and nonsmokers in the one published study examining PD and smoking (Mitchell, 1999). Despite the uncertain relation between PD and smoking, both DD and PD were included in the present study because of the usually high level of correlation between DD and PD and also because of the lack of research examining PD in relation to smoking.

Unfortunately, many of the results from past research to identify predictors of adolescent smoking have been inconsistent across studies (e.g., Flay, d’Avernas, Best, Kersell, \& Ryan, 1983; West \& Michell, 1999). Some argue that such inconsistencies in predictors of adolescent smoking are because researchers have compared smokers versus nonsmokers rather than adopting a more "finegrained" approach that includes an examination of the different stages an adolescent goes through in becoming a regular smoker (e.g., Conrad, Flay, \& Hill, 1992; Flay et al.; Leventhal \& Cleary, 1980). Considering stages of smoking in research examining predictors of adolescent smoking is important because different predictors (in this case different social factors and personality characteristics) may be related to different stages in a manner that would not be apparent within conflated stages. For this reason, the present study examined different stages of adolescent smoking in relation to the different social factors and personality characteristics described above. The following section includes more description of the stages of adolescent smoking and the social factors and personality factors evaluated in the present study. Stages of adolescent smoking

Several authors have proposed models of adolescent smoking that outline the different stages an adolescent is thought to go through in becoming a regular smoker (e.g., Flay et al., 1983; Leventhal \& Cleary, 1980). These models are very similar and basically outline four stages in becoming a regular smoker. See Figure 1 for an outline of these stages. From Figure 1, Preparation and Anticipation refers to the fact that there is a period of preparation for smoking extending back as early 
as the grade school years (e.g., 6 or 7 years of age) that involves the formation of perceptions of the function of smoking and what smoking involves (Leventhal \& Cleary, 1980). These early perceptions set the stage, so to speak, for either positive or negative evaluations of smoking, which ultimately influence the likelihood that an adolescent will try smoking. Never Smokers in Figure 1 are those who never try smoking. Research indicates, however, that few adolescents never try smoking. West and Michell (1999) suggest that as many as 70\% of all adolescents try at least one cigarette by the age of 16 , meaning that those who never try smoking are ultimately a minority contingent when considering the different stages of smoking outlined in Figure 1.

Initiation (trying) in Figure 1 marks the beginning of actual smoking behavior and is defined as the adolescent trying his or her first cigarette (Flay et al., 1983). As mentioned above, the majority of adolescents go through Initiation, with at least $70 \%$ having tried smoking by 16 years of age. Learning/Becoming (experimentation) is defined as the continuation of smoking past the first cigarette, but at a rate of less than one cigarette per week (Flay et al.). Experimentation appears to be an important step in becoming a regular smoker in that 85 to $90 \%$ of the adolescents in the Learning/Becoming stage who smoke four or more cigarettes go on to become regular smokers (Salber, Freeman, \& Abelin, 1968). Habituation/Maintenance (regular smoking) is defined as an increase in the rate of smoking to at least one cigarette per week (Flay et al.).

This process of becoming a regular smoker along the steps outlined in Figure 1 includes the option of quitting at each stage, as represented by the ovals in Figure 1 (e.g., Conrad et al., 1992). At each stage some adolescents quit the process so that ultimately fewer become regular smokers than initially tried smoking. Research also suggests that different factors influence the transitions between the stages depicted in Figure 1. For example, Flay et al. (1983) proposed and others have reported substantial support for (see Conrad et al. for a review) a pattern of influences across the different 


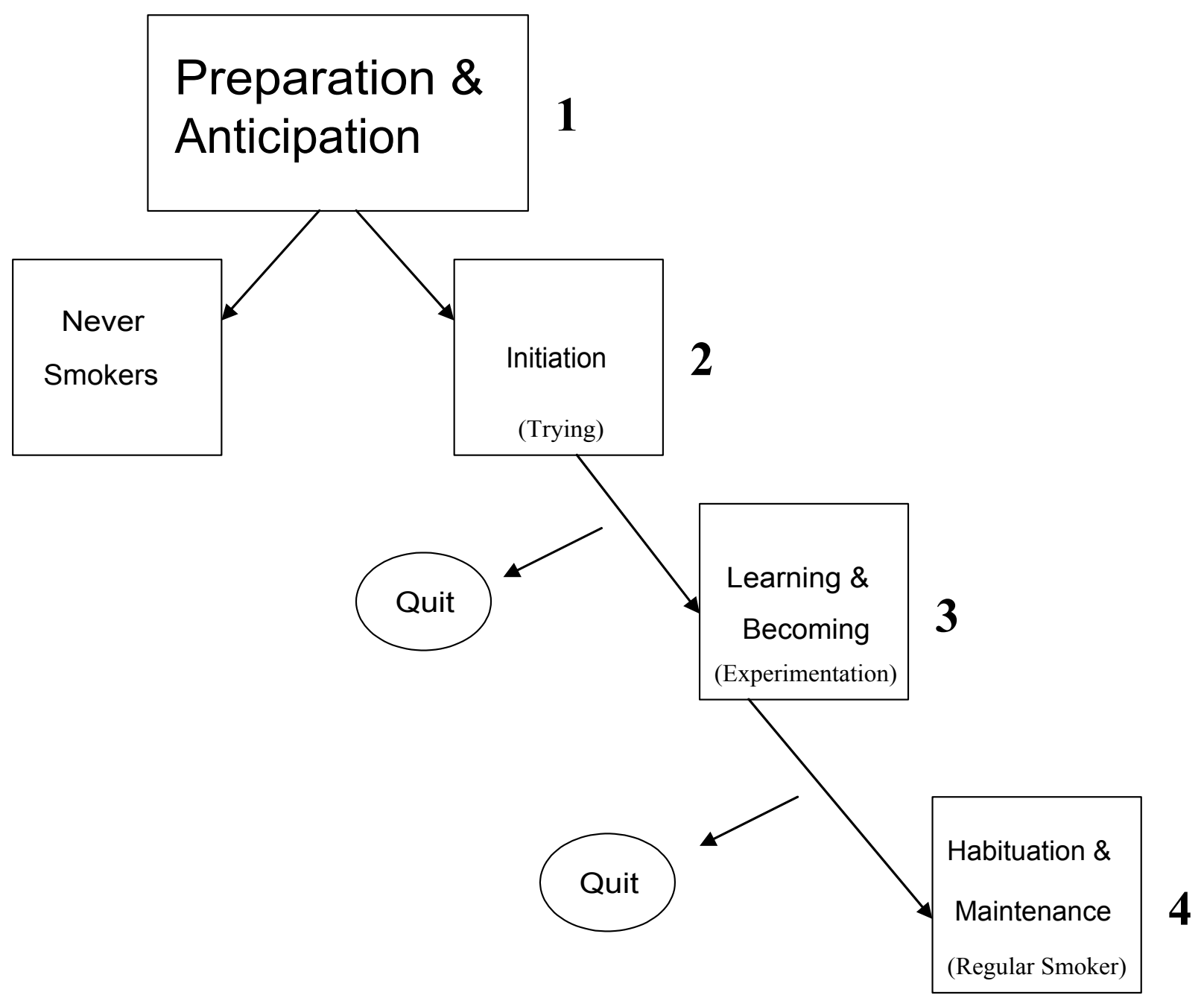

Figure 1. Adolescent stages to becoming a regular smoker, adapted from Flay et al. (1983) 
stages as follows: (a) familial influences are most important during the Preparation and Anticipation stage, (b) peer friends and peer pressure are most influential at the Initiation and Learning/Becoming stages, and (c) individual physiological effects are most important at the Habituation/Maintenance stage, "particularly for certain types of individuals" (Flay et al., p. 145). This pattern of stage-relevant influences hypothesized by Flay and colleagues has received empirical support, but research is still needed to identify additional predictors and to illustrate relations between the stages of smoking outlined in Figure 1 and different predictors (Flay et al., 1994; Mayhew, Flay, \& Mott, 2000; West \& Michell, 1999).

As portrayed in Figure 1, for an individual to become a regular smoker, he or she must pass through each of the previous stages and experience stage-relevant influences that "push" him or her along to the point of ultimately becoming a regular smoker. Inversely, for those who do not become regular smokers, somewhere along the way to becoming a regular smoker (as outlined in Figure 1) an influence (either social or person) important for moving from one stage to another did not occur, thus leading such individuals to quit smoking prior to becoming regular smokers.

The present study was primarily concerned with cross sectionally examining adolescents at several of these different stages of smoking. To facilitate these cross-sectional analyses, participants were recruited who fit grouping criteria meant to approximate some of the different stages outlined in Figure 1. For this study, stage 2-which by definition is trying only one cigarette-and the early part of stage 3-smoking more than one cigarette-were combined to form a single smoking group referred to for the remainder of this document as "triers." Triers were those participants who had smoked at least one but no more than three cigarettes within the last six months. The maximum cutoff of three cigarettes for triers is based on research that has shown that the vast majority of smokers who try at least four cigarettes go on to become regular smokers (Salber et al., 1968). Also, 
for the remainder of this document, participants who quit following stage 3 will be referred to as "past experimenters." These participants were experimenters who ultimately did not become regular smokers, thus allowing an opportunity to examine influences that may have led to quitting during this stage. Therefore, these past experimenters were participants who had smoked more than one cigarette but at a rate less than one cigarette per week. Past experimenters had not smoked any cigarettes for at least six months prior to data collection. Participants at stage 4 will be referred to as “current smokers.” Current smokers were those who currently smoked at least one cigarette a week at the time of data collection. Finally, a group of "never smokers" was included for general comparative analyses between those who had not tried smoking at this age and those who did smoke at other various levels (i.e., stages 2 through 4).

\section{Social Factors}

Adolescent friendships and other social factors stand to be influential in determining smoking behavior during the different phases of adolescent smoking outlined above. During adolescence, friendships have been said to take on a key role in personality and social development as the typical adolescent for the first time encounters intense issues of identity formation and the development of a sense of "self-concept" (e.g., Erikson, 1968; Reynolds, 2002; Rubin, Coplan, Nelson, \& Lagace-Seguin, 1999; Thompson, 1999). Social referencing with peers is particularly important in the self-exploration associated with this age period (Gormly, 1997). Social referencing is a comparison between one's self and others that allows a person to judge his or her own behavior, values, or beliefs in relation to others. Such comparisons stand to facilitate both a sense of independence, formed from comparisons of differences between one's self and certain others, and also relatedness, formed from comparisons of similarities between one's self and others. This 
emphasis on social referencing during adolescence stands to increase similarities between friends of this age period.

From childhood, friends tend to be chosen based on similarities in easily observed characteristics like race, personality, and academic achievement (e.g., Hartup, 1996; Kupersmidt, DeRosier, \& Patterson, 1995; Singleton \& Asher, 1979). In adolescence, friends are more similar in characteristics like attitudes about the use of drugs or alcohol, personality, emotional responsiveness, and academic aspirations (e.g., Diaz \& Berndt, 1982; Hartup, 1983; Savin-Williams \& Berndt, 1990). Also during adolescence, friendships become more exclusive, with a number of friendships dissolving due to lack of compatibility (Rubin et al., 1999). An emphasis on friendship compatibility in adolescence also is suggested by adolescents being more capable than their younger counterparts of accurately describing characteristics of their friends such as personality and typical patterns of behavior (Diaz \& Berndt, 1992). In sum, adolescent friendships differ from friendships at earlier ages in that adolescents increasingly have smaller groups of friends who are more similar on characteristics such as personality and personal values.

Not surprisingly_ given the changing quality of adolescent friendships, the emphasis on social referencing, and sensitivity to friendship compatibility—research on the smoking behavior of adolescents has identified number of friends who smoke as a significant predictor of adolescent smoking (e.g., Allen, Moss, Giovino, Shopland, \& Pierce, 1989; Chassin, Presson, \& Sherman, 1984; Ershler et al., 1989; Rose, Chassin, \&Sherman, 1996). More specific to the present study, research has shown a clear link between number of friends who smoke and adolescent initiation and experimentation with smoking (e.g., Hover \& Gaffney, 1988; Palmer, 1970; Van Roosmalen \& McDaniel, 1989). For example, West, Sweeting, and Ecob (1999) conducted a longitudinal study with 1009 participants to examine the role of various predictors of smoking uptake. Baseline data were 
collected at 15 years of age and followup data were collected at 16, 18, 21, and 23 years of age. The most striking finding was that if a 15-year-old had friends who smoked, he or she was 10 times more likely to try smoking by the age of 16 than a 15 -year-old whose friends did not smoke. This finding was not different for males or females or for different social classes. The same increased probability of starting to smoke if one's friends smoked did not persist through the later years of followup.

In considering the nature of adolescent friendships and research pointing to the importance of number of friends who smoke in predicting smoking behavior, it seems that having friends who smoke may generally influence the transition from one stage to the next for most of the stages as outlined in Figure 1. However, longitudinal research findings have been inconsistent in defining the specific relation between number of friends who smoke and stage of smoking. Some research has shown that having more friends who smoke predicts trying smoking but not regular smoking (e.g., Chassin, Presson, Sherman, Corty, \& Olshavsky, 1984; Flay et al., 1994). Other studies have shown the reverse pattern, with current smokers having more friends who smoke than those individuals who just try smoking (e.g., Ary \& Biglan, 1988; Chassin, Presson, Sherman, Montello, \& McGrew, 1986). Due to the inconsistency of findings in previous research, peer friend smoking behavior was included in the present study.

Other social factors included in the present study were the smoking behavior of those individuals the participants considered to be their best friends, the smoking behavior of the participants' parents or other guardians, and level of parent/guardian education. Best friend smoking behavior is a variable similar to the "number of friends who smoke" variable described above, with a similar rational for inclusion in this study. From the discussion above, it would be predicted that having peer best friends who smoke or who do not smoke would be related to an adolescent's own smoking behavior. Similarly, past research has shown that parent smoking (e.g., Fleming, Kim, 
Harachi, \& Catalano, 2002; Jackson \& Henrikson, 1997) and parent level of education (e.g., Chassin, Presson, Sherman, \& Edwards, 1992) have both been predictive of adolescent smoking behavior, but most of this research has compared only smokers versus non-smokers. Parental smoking and parent level of education were included in the present study for a closer examination of the relation between these two social factors and different phases of adolescent smoking.

\section{Delay and Probability Discounting}

Impulsive behavior as measured by DD or PD has been globally characterized as maladaptive in that an impulsive individual typically does not accurately estimate the consequences of his or her actions (e.g., Richards et al., 1999). These impulsive estimations of consequences are often defined in terms of choice preferences for smaller immediate rewards over larger more delayed rewards (e.g., Logue, 1988; Rachlin, 1989). A preference for immediate smaller rewards can be considered maladaptive in that individuals manifesting such choice preferences ultimately receive less of the total amount of reinforcer than could potentially be received. Measures of DD and PD are procedures to measure choice preferences reflecting impulsivity (e.g., Ainslie, 1975; Racklin, 1995; Racklin \& Green, 1972), which for the present study is hypothesized to reflect an impulsive choice preference for the immediate gratification of smoking cigarettes over the delayed negative health consequences of smoking or the probabilistic consequences for this age group of getting caught smoking.

Relations have been found between rates of DD and chronic cigarette smoking in adults, with chronic cigarette smokers being significantly more impulsive than non-smoking controls (e.g., Bickel et al., 1999; Mitchell, 1999). Relations also have been found between DD and such clinical diagnoses as substance dependence and abuse, borderline personality disorder, bipolar disorder (e.g., Crean et al., 2000), and alcoholism (e.g., Vuchinich \& Simpson, 1998). In each comparison, the clinical groups showed a greater impulsive tendency in DD than controls. 
For the present study, DD and PD were included in the evaluation of different phases of adolescent smoking in part because of the relation between DD and smoking in adults and also in part due to the observation that despite adolescent smokers reporting that they know about the healthrelated risks of their smoking (e.g., Charlton, 1984), they continue to smoke. Adolescents have given reasons for their smoking such as doing it for the stimulation of the experience, for the pleasure of the experience, and for relaxation (e.g., Ikard, Green, \& Horn, 1969), all of which emphasize the immediate personal benefits of smoking. If viewed from the perspective of DD or PD, adolescent smokers who are in a position to decide between either continuing to smoke or not to smoke have a choice between the delayed and probabilistic consequences of continuing to smoke (i.e., health problems associated with smoking) versus the immediate gratification of smoking, as do adult smokers. Also, as mentioned above, adolescents who decide to try smoking or to continue smoking are discounting the probabilistic consequence of getting caught smoking in favor of the nonprobabilistic immediate benefits of smoking described above. For these reasons, DD and PD were both included in the present study and represent tenable new dimensions of behavior to be studied in relation to different stages of adolescent smoking.

In sum, the present study sought to examine the relations between different stages of adolescent smoking and the person characteristics of DD and PD and the social factors of peer friend smoking behavior and parent/guardian characteristics regarding smoking and level of education. In examining these different person and social factors during different stages of adolescent smoking, it is believed that different factors may be more or less related to smoking during the different stages an adolescent goes through in ultimately becoming a regular smoker. In the next section are specific hypotheses as to what some of these relations may be. 
Hypotheses

From the discussion above, two primary hypotheses become apparent. First, it was hypothesized that measures of impulsivity would differentiate between adolescent current smokers and never smokers, past experimenters, and triers_-with current smokers being most impulsive. Further, it was hypothesized that those participants who had not tried smoking and those who were triers or past experimenters would not differ significantly in impulsivity. This hypothesis basically reflects an expectation based on research with adults that shows a clear distinction between smokers and nonsmokers on DD. Second, it was hypothesized that those participants who had never tried smoking or who were past experimenters would have fewer friends who smoke than those participants fitting either the criteria for triers or current smokers. As a corollary, it was hypothesized that never smokers and past experimenters would not differ significantly in the number of friends they had who smoke, and triers and current smokers would not differ significantly in their number of friends who smoke. These hypotheses basically reflect an expected pattern of active smoking being associated with having more friends who smoke. Therefore, those participants who had not been smoking for some time prior to data collection (i.e., never smokers and past experimenters) should have fewer friends who smoke than participants smoking within a time frame recent to data collection.

Additional analyses included comparisons of male and female participants within each of the four smoking groups on impulsivity and number of friends who smoke. Gender was a person variable worth examining in relation to impulsivity in that some research has shown females to be less impulsive on average than males (e.g., Koda, 1999). Also, gender differences in high school students have been found in the relation between paper and pencil measures of impulsivity and the use of alcohol, caffeine, and nicotine (Waldeck \& Miller, 1997). Higher impulsivity was predictive of alcohol and caffeine use but not nicotine use in males. For females, higher ratings of impulsivity were 
predictive of alcohol and nicotine use but not caffeine use. For the present study, it was not known how DD and PD may relate differently to smoking in adolescent females versus adolescent males; therefore there were no specific hypotheses for these comparisons.

Also, past research that has examined gender differences in number of friends who smoke has used somewhat different smoking group criteria; therefore, in the present study, gender differences in number of friends who smoke were analyzed within the different smoking groups. However, because past research has shown little relation between gender and number of friends who smoke in predicting trying smoking or becoming a regular smoker (e.g., Flay et al., 1994; West \& Michell, 1999; West, Sweeting, \& Ecob, 1999), no specific hypotheses were proposed for these analyses. Correlational analyses were conducted using all participants to examine relations between responses to the DD and PD tasks. Based on adult research, most of which finds DD and PD to be correlated, it was hypothesized that measures of DD and PD would be significantly correlated in the current study.

Finally, parent smoking behavior and parent level of education were examined as possible predictors of adolescent smoking status. Research has shown that adolescents who smoke are more likely to report having parents who also smoke than are adolescents who do not smoke or who have tried smoking but did not go on to smoke regularly (e.g., Fleming, Kim, Harachi, \& Catalano, 2002; Jackson, Henrikson, 1997; White, Pandina, \& Chen, 2002). For this reason, it was hypothesized that current smokers would report more often than never smokers or past experimenters that one or both of their parents also smoke. Also, it was expected that the relation between parent level of education and adolescent smoking status would reflect the pattern found in previous adolescent smoking research with adolescents from lower socioeconomic status (SES) conditions being more likely to smoke (e.g., Cleary et al., 1988; Scrinci, Robinson, Alfano, Zbikowski, \& Klesges, 2002). Assuming a positive relation between parent education and SES in this sample, it was hypothesized that lower 
levels of parent education would predict more adolescent smoking. For the purposes of the present study, relations between other demographic variables and smoking group status were not examined.

\section{Participants}

\section{Method}

Seventy five high school students (35 males and 40 females) ranging between 14 and 16 years of age, with an average age of 15.10 years $(\mathrm{SD}=.67)$, were recruited from one rural high school in West Virginia. All but two of the participants reported being "white." The other two participants reported being "black." The grouping criteria for the triers and past experimenters was modified to include participants who had smoked as many as10 cigarettes-though the most cigarettes smoked by any of the triers was only 6 cigarettes. This was done because of (a) difficulty in recruiting enough participants who had specifically smoked 3 or fewer cigarettes, and also because (b) the participants in the current smoker group smoked sufficiently high numbers of cigarettes that it led to clear distinctions between current smokers and triers or past experimenters. The average number of cigarettes reported to have been smoked by participants in the trier and past experimenter groups were roughly equivalent-within one cigarette of each other.

Never smokers ( $\mathrm{n}=19 ; 10$ females) were those who had not tried smoking even one cigarette. Triers ( $\mathrm{n}=17 ; 9$ females) were those who had only tried cigarettes during the six months prior to data collection. The average number of cigarettes smoked by the participants in the trier group was 3.76 $(\mathrm{SD}=1.48)$ cigarettes, with the range spanning from 1 to 6 cigarettes. Past experimenters $(\mathrm{n}=20 ; 12$ females) were those who tried cigarettes in the past, but who had not smoked any cigarettes for the six months prior to data collection. The average number of cigarettes smoked by the participants in the past experimenter group was $3.75(\mathrm{SD}=2.83)$ cigarettes, with the range spanning from 1 to 10 cigarettes. The final group included current smokers ( $\mathrm{n}=19 ; 9$ females), who smoked every week for at least six months prior to data collection. The average number of cigarettes smoked per week by the 
participants in the current smoking group was $46.42(\mathrm{SD}=25.11)$ cigarettes, with a range from 12 to 100 cigarettes a week. The six-month limit imposed on this group was to ensure that the specified pattern of smoking had been stable for an extended period.

Participants were recruited via letters to parents and descriptive flyers sent home with age-appropriate students (see Appendix A). Students were told to take the materials home for review with their parents/guardians and to return the informed consent form signed by a parent/guardian if they qualified to participate and if they wanted to participate. These materials were sent home with 270 students. Students who returned signed informed consent forms (approximately 150 students) were tentatively categorized into one of the four smoking groups by a paid $(\$ 200)$ school representative assisting with data collection until each group had approximately 20 participants. Students who returned consent forms after the smoking group they qualified for was considered "full" did not participate in the study. See Appendix B for the informed consent and assent forms. Final screening for participant inclusion was based on participant responses to demographic questions regarding current smoking behavior and smoking history (see Appendix C), which were reviewed following data collection. Research has shown that participant self reports of smoking behavior are a valid estimate of participant smoking when checked against CO recordings (e.g., Wills \& Cleary, 1997). For the present study, only participant self reports of smoking behavior were used to classify participants according to the different smoking categories of the study. Participants who did not meet inclusion criteria in the final stage of screening $(n=12)$ participated in all data collection and received payment; however, their data were not retained for analyses.

Participants received different amounts of money for their participation. Amount of money received for participation depended on choices made during the task procedure for DD and PD (see 
below for description of task). The amount of money received for participation ranged between $\$ 10$ and $\$ 20$ each. Institutional Review Board approval was obtained prior to the beginning of the study. Procedure

Total participation time for each participant was approximately 30 minutes. Data were collected in small groups in a computer lab at the high school where recruitment took place. All data were collected in the same computer lab, but data collection took place on three different days within a 2-month period. Participants were seated along tables in the computer lab, with each participant stationed at a desktop computer. Seating was assigned in advance in an effort to avoid having friends sitting with each other, and participants were asked to not talk before or during participation. Participants were first given some basic instructions (see Appendix D for outline of instructions) and then asked to complete the computerized task for DD and PD (see description of task below). As a part of the instructions, participants were told that they were all doing "somewhat different" version of the computer program, and that for that reason, they would be finishing the program after different lengths of time. This part of the instructions was an effort to reduce comparisons made by participants between self and others during participation. All of the questions for assessing DD and PD were completed during one computer session, which randomly presented either DD or PD questions until degree of discounting had been determined for both measures. This task with instructions took approximately 15 minutes to complete.

Following the computerized task, participants were asked to complete the demographic questionnaire that included, among other things, questions concerning number of friends who smoke and the participant's own smoking behavior (see Appendix C). This questionnaire was completed at the computer station where participants had completed the computerized task. The questionnaire and a pen were already at the computer station when the participant originally sat down for participation. 
After participants completed the questionnaire, they went to another room where one of their responses to the computerized task for DD or PD was selected at random with a random number generator available via the Internet. All participants received at least $\$ 10$ at the end of the participation session just for participating. Participants received an additional amount of money (between $\$ 0$ and \$10) either immediately or after a delay as specified by his or her randomly selected answer given during the computerized task. If the selected answer was from a DD question involving delay (e.g., \$5 in 180 days), the money was placed in an envelope labeled with the participant's name and address and mailed to him or her after the specified delay. If, on the other hand, the selected answer was from a PD question (e.g., $25 \%$ chance for $\$ 10$ ), then two colors of poker chips were placed in a bag reflecting the specified proportions ( 1 red chip and 3 blue chips). The participant drew a chip from the bag to determine if the money was to be received. This procedure for determining participant payment was described to the participants in detail prior to their completing the computerized task (see Appendix D).

\section{Questionnaire Variables}

Demographic Questionnaire. See Appendix C for the demographic questionnaire. Included in this questionnaire were questions regarding basic participant demographic information and questions about current or past smoking behavior. Also, there was a friendship question about the number of friends the participant had who smoked. The format of this friendship question was taken from West and Michell (1999).

\section{Choice Task Variables}

Delay Discounting Choice Task. As already described, discounting by delay is by definition the extent to which an organism "discounts" the value of a reinforcer as a function of delay to its delivery. Discounting of value as a function of delay is typically assessed through commitment choice 
procedures, which means that once a choice has been made it cannot be reversed and does not need to be sustained. Commitment choice procedures have primarily been developed for the study of choice behavior, whereby an organism can choose between a large reinforcer received after a delay or a smaller reinforcer received either immediately or after a short delay. For humans, DD is assessed through a series of questions that are worded as follows: "Would you rather receive $\$ 10$ in 30 days, or would you rather receive $\$ 2$ now”? Choice responses reflecting a tendency for more immediate smaller reinforcers over delayed larger reinforcers are interpreted as a devaluation of a reinforcer as a function of the delay to its delivery (Mazur, 1987).

Assessing DD involves determining indifference points between larger reinforcers delivered after different temporal delays and smaller more immediate reinforcers. An indifference point is the point at which two reinforcers (i.e., a large reinforcer delivered after a delay and a smaller more immediate reinforcer) have equivalent reinforcing effectiveness or are of equal subjective value. Indifference points obtained across a series of different delay periods are used to plot discount curves for delay, which represent the rate of reinforcer discounting that occurs as a function of increasing the delay to its delivery. Discount curves for delayed reinforcers have been characterized most efficiently in humans, rats, and pigeons by Mazur's (1987) hyperbolic function:

$$
\mathrm{V}=\mathrm{A} /(1+k \mathrm{D})
$$

where $\mathrm{V}$ represents the value of the delayed reinforcer, and $\mathrm{A}$ and $\mathrm{D}$ are the amount of reinforcer and length of delay to its delivery, respectively. The $k$ is a free parameter. The $k$ indicates the steepness of the discount curve, with higher $k$ values indicating more rapid discounting. The value of $k$ obtained using procedures to assess DD has been defined to represent impulsivity, with larger values of $k$ indicating higher levels of impulsivity (e.g., Evenden, 1999; Logue, 1988; Monterosso \& Ainslie, 1999; Richards et al., 1999). Higher $k$ values reflect a preference for more immediate smaller reinforcers at 
the expense of total reinforcers earned. It is the $k$ value of Equation 1 that is typically examined in relation to other variables of interest (see Introduction).

For the present study, a computerized procedure as described above was used for assessing DD (see Richards et al., 1999). The task was used to determine indifference points for five different delay periods: $1,2,30,180$, and 365 days. The program presented a series of questions that ask the participant to decide between $\$ 10$ to be received after one of the five different delay periods or a smaller amount (e.g., \$2) that could be received immediately. The smaller amount of immediate money was adjusted up or down by the program until an indifference point was arrived at for each of the delay periods. The indifference points for all five delay periods were used to calculate delay discount curves (i.e., Equation 1).

Probability Discounting Choice Task. In procedures to measure PD, the participant is presented with choice options between larger, more preferred reinforcers that are less probable and smaller, less preferred reinforcers that are more probable. The questions for assessing PD are worded as follows: "Would you rather have a $60 \%$ chance of receiving $\$ 10$, or a $100 \%$ chance of receiving $\$ 2$ "? The outcome measure of interest in PD is the extent to which a person discounts the larger reinforcer as a function of a decreasing probability of its delivery. Indifference points and discount curves can be derived from PD procedures just as they are for DD procedures. Like with discount curves for delay, the pattern of discounting as a function of probability is best characterized by a hyperbolic model (Rachlin, Raineri, \& Cross, 1991). The hyperbolic discount function for probability discounting is calculated as follows:

$$
\mathrm{V}=\mathrm{A} /(1+b O), \mathrm{O}=(1 / p)-1
$$

where $p$ and $O$ are inversely related. The $p$ represents the probability of receiving the reinforcer and the $O$ stands for odds against receiving the reinforcer. From this calculation, $b$ indicates rate of discounting 
as a function of decreasing probability of receiving the larger reinforcer. Higher $b$ values represent a more rapid rate of discounting and thus greater impulsivity. The $b$ value of Equation 2 is analogous to the $k$ value of Equation 1.

For the present study, the same computerized procedure as used for assessing DD was used to assess PD. Indifference points were determined for five different probability values: $1.0, .9, .75, .5$, and .25. Questions for establishing PD required the participant to decide between a particular probability of receiving $\$ 10$ (e.g., .25 chance) or a smaller amount to be received for sure. The smaller amount of certain money was adjusted up or down by the program until an indifference point was arrived at for each of the probabilities. Indifference point values were used to calculate probability discount curves (i.e., Equation 2).

\section{Results}

First hypothesis (Explore DD and PD scores in relation to gender and stage of cigarette smoking)

In this analysis, there were two steps ultimately leading to an analysis of group differences (never smokers, triers, past experimenters, and current smokers) in both DD and PD. In the first step, a nonlinear curve-fitting program (Origin 6.0, 1999) was used to determine each participant's best fit values of $k$ and $b$ from Equations 1 and 2, respectively.

For the second step in the analysis, a between subjects two-way analysis of variance (ANOVA) was performed for DD comparisons, and a separate between subjects two-way ANOVA was performed for PD comparisons. For these analyses, smoking group category was a grouping variable, and gender was a second grouping variable for both tests. Log transformed $k$ and $b$ values were the different test values for the analyses. A $\log$ transformation was required for these data due to their being nonlinear, which would be inappropriate for the ANOVA without a transformation. Bonferroni 
tests were used for followup testing. One-way ANOVAs were also performed with the raw indifference point data to examine possible smoking group difference in both PD and DD data.

Figures 2 and 3 are graphs of the overall group DD and PD functions, respectively. The $\mathrm{R}^{2}$ values for the different discount functions for DD (.66 to .93) and PD (.84 to .94) represent the variance accounted for by equations 1 and 2. Some researchers have used an $R^{2}$ value of .60 as a cutoff value for data inclusion (e.g., Critchfield, 2001). By this standard, both types of discounting were characterized well by equations 1 and 2. The between subjects two-way ANOVA with individual data for DD showed no significant interactions, nor was there a significant main effect for gender or for smoking group status in $k$ values. For PD, there also was no significant interaction, and gender showed no significant effect on $b$ values. However, there was a significant effect for smoking group status, $F(3,72)=3.02, p<.05$. From Bonferroni post-hoc analyses, the only significant difference was between never smokers and triers $(p<.05)$, with triers having significantly higher $b$ values than never smokers (see Figure 3). There were no significant group differences in either DD or PD indifference points.

Second hypothesis (Explore number of friends who smoke in relation to gender and stage of cigarette smoking)

A between subjects two-way ANOVA was performed with smoking group category as one grouping variable and gender as the other grouping variable. The number of friends who smoke, determined from the demographic questionnaire (see Appendix A), was the test value for these analyses. Bonferroni tests were used for followup analyses.

The two-way ANOVA showed no significant interaction between smoking group status and gender for number of friends who smoke. However, there was a significant smoking group effect, $F(3$, $74)=10.35, p<.001$, but there was no significant gender effect. Table 1 shows the Bonferroni 
post-hoc analyses, which reveals that current smokers reported having more friends who smoke than never smokers or past experimenters. Also, triers reported having more friends who smoke than never smokers; however, triers and current smokers did not differ significantly, nor did never smokers and past experimenters. Also, triers and past experimenters did not differ significantly.

Secondary analyses (Explore relations between $D D$ and $P D$, between age and $D D$ and $P D$, and between stage of cigarette smoking and answers to questions about parents and friendships)

To examine the relation between DD and PD, a Pearson's correlation coefficient was calculated using $\log$ transformed $k$ and $b$ values. Log transformed values of $k$ and $b$ were significantly correlated, $r(73)=.63, p<.001$. A Pearson's correlation coefficient also was performed to examine relations between age and $k$ and $b$ values. There was no significant correlation between age and $\log$ transformed $k$ or $h$ values. A one way ANOVA was performed to test for age differences between the different smoking stage groups. There were no significant age differences. Also, ANOVA analyses for gender differences in values of $k$ or $b$ revealed no significant gender differences.

More specific friendship questions (i.e., (a) smoking stage of best friend and (b) smoking practices of male versus female friends) were examined in relation to stage of participant smoking. Chi-square analyses were used to examine the relation between the four smoking stage groupings of participants and the four possible best friend smoking categories. Asymptotic Chi-square analyses were not performed, however, because 9 cells had expected values less than 5 , which is a violation of the assumptions for this test. Instead, a Fisher's Exact Chi-square was performed, which was more appropriate for these data. Table 2 shows the Chi- square table for participant smoking group status and the smoking status of the participant's best friend. These analyses showed that participant smoking group status and best friend smoking behavior were significantly related, $\mathbf{X}^{2}(9, \mathbf{N}=74)=$ 


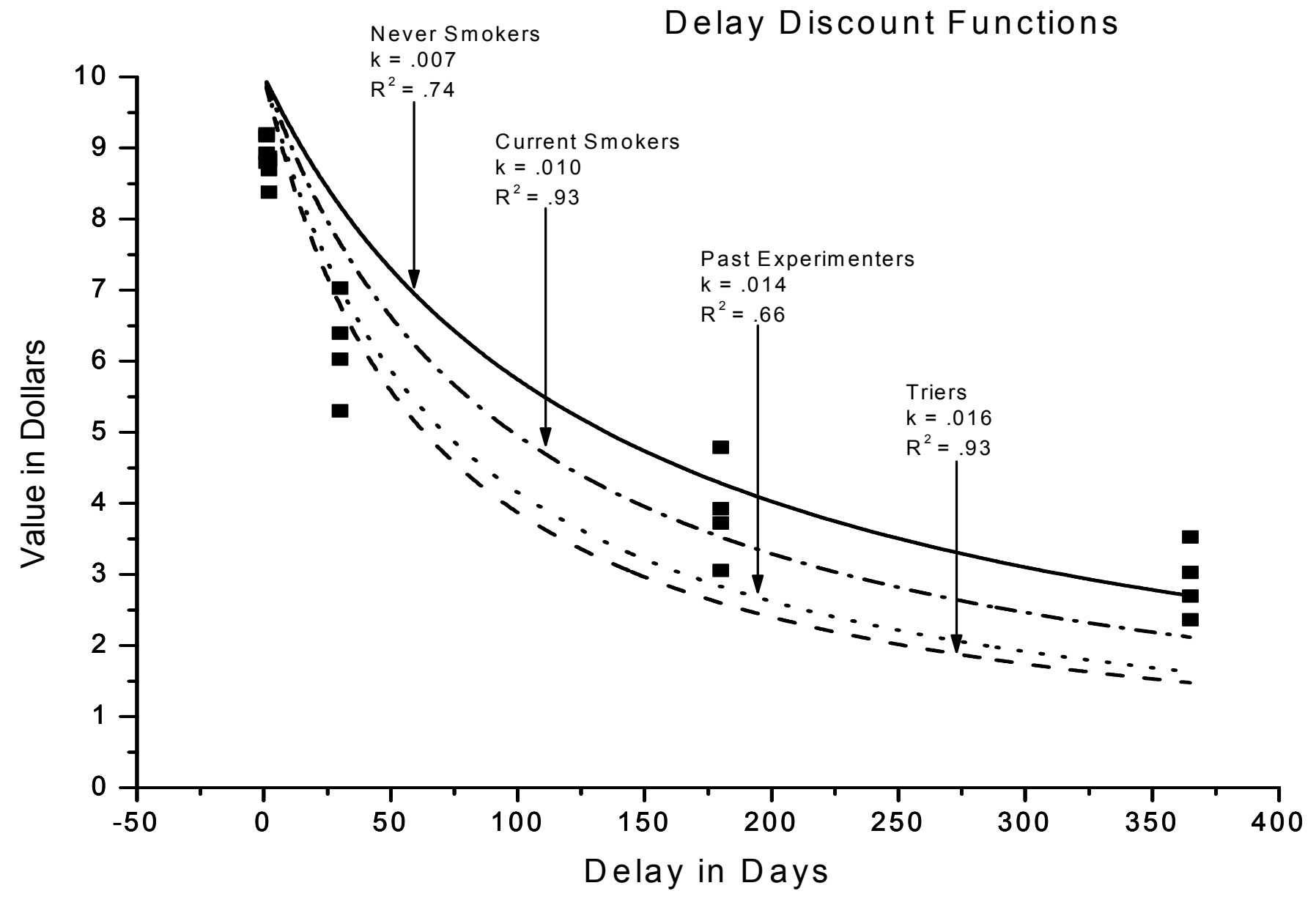

Figure 2: Best fit delay discount functions for four different experimental groups 


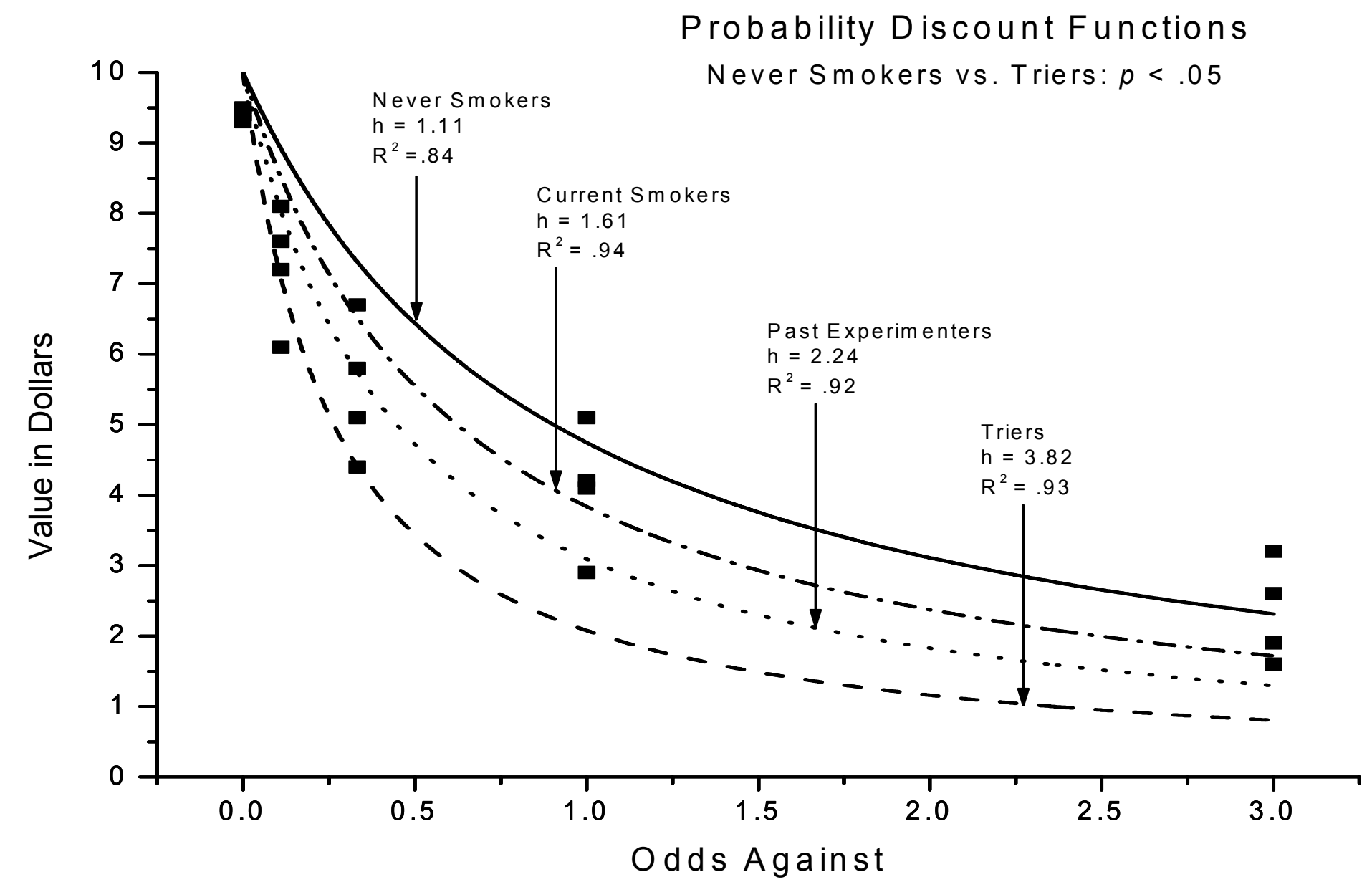

Figure 3: Best fit probability discount functions for four different experimental groups 
Table 1

Post-Hoc Findings for Main Effect of Smoking Status and Number of Friends Who Smoke

\begin{tabular}{lll}
\hline Smoking Group & Mean & $(S D)$ \\
\hline Never Smokers & $2.00_{\mathrm{a}}$ & $(.58)$ \\
Triers & $2.71_{\mathrm{b}, \mathrm{c}}$ & $(.85)$ \\
Current Smokers & $3.37_{\mathrm{b}}$ & $(.83)$ \\
Past Experimenters & $2.45_{\mathrm{a}, \mathrm{c}}$ & $(.83)$ \\
\hline
\end{tabular}

Note. Mean values are based on a Likert-like scale for friends who smoke ranging from 1 (none of my friends smoke) to 5 (all of my friends smoke). Means with different subscripts differ significantly at $p<.05$. 
39.85, $p<.001$. From Table 2 , it can be seen that the largest numbers in each column and row correspond with the matching smoking group (highlighted cells), except in the case of triers and past experimenters.

As a followup to the overall Chi-square analysis for smoking group status and the smoking behavior of a participant's best friend, trier and current smoker groups were combined and the past experimenter and never smoker groups were combined to form two new groups, one with participants who were smoking at some level at the time of data collection and a second group that was not smoking at the time of data collection. Also, the corresponding best friend smoking categories were combined so that best friends were either smoking at the time of data collection (currently smoking or just tried recently) or they were not smoking (never tried or tried in the past). A 2 X 2 Chi-square analysis revealed that participant smoking behavior and the smoking behavior of best friends were significantly related, $\mathbf{x}^{2}(1, \mathrm{~N}=74)=10.5, p<.001$ (see table 3$)$.

To examine any possible gender differences across the four smoking groups in having more male or more female friends who smoke, independent sample $t$-tests were performed comparing the percentage of male friends who smoke and the percentage of female friends who smoke for male and female participants collapsed across all four smoking groups. Paired samples $t$-tests were performed to examine gender differences in having male or female friends who smoke within each smoking group. Independent $t$-tests also were performed to check for gender differences in reported parent smoking and also for gender differences in reported best friend smoking behavior. The independent sample $t$ test performed on the collapsed friendship data across all smoking groups showed no significant gender differences in having male versus female friends who smoke. $t$-tests performed within each smoking group did, however, show that male current smokers reported having more male 
Table 2

Comparison Table for Participant Smoking Status and Smoking Behavior of Best Friends

\begin{tabular}{|c|c|c|c|c|c|}
\hline & & \multicolumn{2}{|c|}{ Best Friend } & \multirow[b]{2}{*}{ Smokes } & \multirow[b]{3}{*}{ Total } \\
\hline Participant & Has Never & Recently & Tried in & & \\
\hline Groupings & Smoked & Tried & the Past & Regularly & \\
\hline $\begin{array}{l}\text { Never } \\
\text { Smoker }\end{array}$ & 9 & 3 & 6 & 1 & 19 \\
\hline Triers & 3 & 5 & 7 & 2 & 17 \\
\hline $\begin{array}{c}\text { Past } \\
\text { Experimenters }\end{array}$ & 5 & 2 & 9 & 3 & 19 \\
\hline $\begin{array}{l}\text { Current } \\
\text { Smokers }\end{array}$ & 1 & 0 & 3 & 15 & 19 \\
\hline Total & 18 & 10 & 25 & 21 & 74 \\
\hline
\end{tabular}

Note. The highlighted numbers represent largest row and column numbers, except between past experimenters and triers. 
Table 3

Comparison Table for Participants Who Smoke Versus Do Not Smoke and the Smoking Behavior of Best Friends

\begin{tabular}{|l|c|c|c|}
\cline { 2 - 4 } \multicolumn{2}{c}{} & \multicolumn{2}{c|}{ Best Friend } \\
\hline Participant Groupings & $\begin{array}{l}\text { Never Tried/Tried in } \\
\text { Past }\end{array}$ & $\begin{array}{l}\text { Current/Recently } \\
\text { Tried }\end{array}$ & Total \\
\hline $\begin{array}{l}\text { Never Smokers and } \\
\text { Past Experimenters }\end{array}$ & 29 & 14 & 43 \\
\hline $\begin{array}{l}\text { Current Smokers and } \\
\text { Triers }\end{array}$ & 9 & 22 & 31 \\
\hline \multicolumn{1}{|c|}{ Total } & 38 & 36 & 74 \\
\hline
\end{tabular}


friends who smoke than they did female friends who smoke, $t(9)=3.97, p<.01$. This was the only significant difference in all the comparisons (see Table 4 for means).

To explore relations between adolescent smoking status and parent smoking behavior, an asymptotic Chi-square analysis was performed between parent smoking behavior (i.e., yes or no) and the four adolescent smoking groupings. Chi-square analyses showed no significant relation between the smoking behavior of mothers and adolescent smoking group status (see Table 5); however, there was a significant relation between the smoking behavior of fathers and adolescent smoking group status, $\mathbf{X}^{2}(3, \mathbf{N}=74)=8.94, p<.05$. See Table 5 for the Chi-square table. Table 6 shows that father smoking was substantially less frequent for the never smokers and past experimenters than it was for the other two groups. About half of the fathers smoked in the triers and current smokers groups.

To explore relations between parent education and adolescent smoking group status, an ANOVA was used with Bonferroni post hoc tests as followup analyses. Parent education was coded along a 5 -point scale, ranging from $1=$ some high school to $5=$ graduate or professional degree (see Appendix A). ANOVA analyses showed no significant main effect of adolescent smoking group status on mother's level of education but did show a significant main effect of smoking group status on father's level of education, $F(3,70)=4.67, p<.05$. Post hoc analyses showed that the fathers of adolescents in the never smoker group had significantly more education than the fathers of participants in the current smoker group or the trier group, $p^{\prime}$ s $<.05$ (see Table 7). There were no other significant differences. The variables of father education and father smoking were not significantly correlated.

Finally, between groups $t$-tests were performed to determine if there were gender differences in the smoking behavior of participants' mothers, fathers, or best friends within each of the smoking groups. No gender differences were found. 
Table 4

Number of Male Versus Female Friends Who Smoke Within Each Smoking Group Category

Smoking Group $\quad$ Participant Gender $\quad$ Friends Who Smoke Mean(SD)

\section{Never Smokers}

$\begin{array}{lll}\text { Male } & \begin{array}{l}\text { Female Friends } \\ \text { Male Friends }\end{array} & 1.67(.50) \\ & & 2.11(.78) \\ \text { Female } & \text { Female Friends } & 1.90(.57) \\ & \text { Male Friends } & 2.00(.82)\end{array}$

Triers

$\begin{array}{lll}\text { Male } & \begin{array}{l}\text { Female Friends } \\ \text { Male Friends }\end{array} & 2.13(.35) \\ & & 2.25(.46) \\ \text { Female } & \text { Female Friends } & 2.78(.83) \\ & \text { Male Friends } & 2.89(.93)\end{array}$

Past Experimenters

$\begin{array}{lll}\text { Male } & \begin{array}{l}\text { Female Friends } \\ \text { Male Friends }\end{array} & 2.00(.53) \\ & & 2.38(.74) \\ \text { Female } & \text { Female Friends } & 2.25(.75) \\ & \text { Male Friends } & 2.83(.94)\end{array}$

Current Smokers

$\begin{array}{lll}\text { Male } & \begin{array}{l}\text { Female Friends } \\ \text { Male Friends }\end{array} & 2.90(.88) \\ & & 4.00(.47) \\ \text { Female } & \text { Female Friends } & 3.00(.87) \\ & \text { Male Friends } & 3.00(1.12)\end{array}$

Note. Mean values are based on a Likert-like scale for female friends who smoke and for male friends who smoke ranging from 1 (none of my male/female friends smoke) to 5 (all of my male/female friends smoke)

$* p<.05$ 
Table 5

Comparison Table for Participant Smoking Status and Smoking Behavior of Participant's Mother

\begin{tabular}{|l|c|c|c|c|c|}
\cline { 3 - 6 } \multicolumn{2}{c|}{} & \multicolumn{4}{c|}{ Smoking Group Category } \\
\hline $\begin{array}{l}\text { Mother } \\
\text { Smoking }\end{array}$ & $\begin{array}{l}\text { Never } \\
\text { Smokers }\end{array}$ & Triers & Past & Turrent \\
Smokers & Total \\
\hline Yes & 5 & 8 & 11 & 10 & 34 \\
\hline No & 14 & 9 & 8 & 8 & 39 \\
\hline Total & 19 & 17 & 19 & 19 & 74 \\
\hline
\end{tabular}


Table 6

Comparison Table for Participant Smoking Status and Smoking Behavior of Participant's Father

\begin{tabular}{|l|c|c|c|c|c|}
\cline { 3 - 5 } \multicolumn{2}{c}{} & \multicolumn{3}{c|}{ Smoking Group Category } & \multicolumn{1}{c|}{} \\
\hline $\begin{array}{l}\text { Father } \\
\text { Smoking }\end{array}$ & $\begin{array}{c}\text { Never } \\
\text { Smokers }\end{array}$ & Triers & $\begin{array}{c}\text { Past } \\
\text { Experimenters }\end{array}$ & $\begin{array}{c}\text { Current } \\
\text { Smokers }\end{array}$ & Total \\
\hline Yes & 3 & 8 & 5 & 11 & 27 \\
\hline No & 16 & 9 & 14 & 8 & 47 \\
\hline Total & 19 & 17 & 19 & 19 & 74 \\
\hline
\end{tabular}


Table 7

Mother and Father Level of Education for Participants in Each Smoking Group Category

Smoking Group Parent $\quad$ Education: Mean(SD)

Never Smokers

Father

$3.06(1.11)$

Mother

$2.61(.85)$

Triers

Father

$2.06(.65)$

Mother

$2.30(.82)$

Past Experimenters

Father

$2.32(1.11)$

Mother

$2.69(1.25)$

Current Smokers

Father

$1.94(.97)$

Mother

$2.39(.98)$

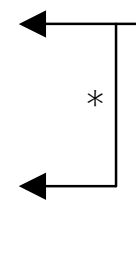

$*$ 
Hypotheses

Discussion

The hypothesis that measures of DD and PD would differentiate between current smokers and the other three smoking groups was not supported by the results of the present study. As can be seen in Figures 2 and 3, the between-group pattern was the same for both DD and PD, and the two measures were significantly correlated. However, on measures of DD, none of the groups differed significantly. On measures of PD, though, the never smokers and triers did differ significantly, with triers discounting more steeply than never smokers (see Figure 3). This finding with PD is different than what was hypothesized in that current smokers were originally hypothesized to be most impulsive, but triers were actually most impulsive. This unexpected finding may imply that more impulsive adolescents are more likely than others to try cigarettes, but that impulsivity is not related to the progression from trying to experimenting with to regularly using cigarettes.

The hypothesis that those who smoke would have more friends who smoke was largely supported by the results of the present study (see Table 1). As hypothesized, (a) triers and current smokers reported having more friends who smoke than did never smokers; (b) current smokers reported having more friends who smoke than did past experimenters; (c) current smokers and triers did not differ significantly; and (d) never smokers and past experimenters did not differ. However, triers and past experimenters also did not differ significantly from each other in number of friends who smoke, and it was hypothesized that triers would report having more friends who smoke than would past experimenters. This finding suggests that the number of friends an adolescent has who smoke or who do not smoke may not play a significant role in a trier deciding not to continue smoking. However, the pattern in these data may also suggest that number of friends who smoke does contribute to some triers becoming regular smokers-in that current smokers had more friends who smoke than did past experimenters. Otherwise, the number of friends an adolescent had who smoke 
corresponds fairly closely with his or her own smoking behavior. If participants were currently smoking at the time of participation (i.e., current smokers or triers), they did not differ significantly from each other in the number of their friends who also smoked. Similarly, if the participants were not currently smoking (e.g., never smokers or past experimenters), they were similar to each other in that most of their friends also did not smoke.

There was no relation between gender and either discounting or number of friends who smoke, which suggests that gender differences in discounting or number of friends who smoke may not play a significant role in the smoking behavior of adolescents. However, friendships examined within each smoking group category revealed that male current smokers reported having more male than female friends who smoke. This same pattern was not found for female regular smokers. That male adolescent smokers tended to have more male than female friends who smoke implies that smoking may be a shared activity among males, which fits the general characterization of male friendships as oriented around shared activities (e.g., Berndt, 1982) relative to female friendships that tend to be more oriented around shared intimacy (e.g., Berndt, 1992). By extension, if the act of smoking in male-to-male friendships among adolescent current smokers serves to facilitate or support the friendship, then male-to-male friendships involving smoking would be an important variable in the maintenance of male adolescent regular smoking and would need to be considered in any intervention to reduce cigarette smoking in this group.

Some of the secondary hypotheses were supported while others were not. Measures of DD and PD were significantly correlated, which was expected. Also, an association was found between participant smoking status and the reported smoking behavior of the participant's best friend; though, again, this relation was weak for those participants just recently trying cigarettes. The relation between best friend smoking behavior and participant smoking status was particularly strong for the never 
smokers and the current smokers. Most of the best friends of never smokers had either never tried smoking or had tried in the past, but they were not currently smoking at the time of data collection and therefore matched the smoking behavior of the participant. Similarly, current smokers largely reported having best friends who also smoked. Additional analyses with collapsed date showed even more clearly a significant relation between smoking and having friends who smoke (see Table 3). The pattern of these findings is consistent with the understanding of adolescent friendships as being selective on the grounds of values about things like school and drug use (e.g., Diaz \& Berndt, 1982; Hartup, 1983; Savin-Williams \& Berndt, 1990) and therefore supports the position that adolescents gravitate towards friendships that support their values and behaviors concerning smoking.

No overall age or gender effects for DD or PD were found, which previous research has shown in some instances. The range of ages for the present study was likely not sufficient to produce detectable age differences. Also, gender differences in discounting have been spotty in past research, with some studies showing gender differences (e.g., Kirby \& Marakovic, 1996) and other studies not showing gender differences (e.g., Logue \& Anderson, 2001). Therefore, not finding gender differences in the present study is not necessarily inconsistent with previous findings.

Finally, with respect to possible parent influence, father smoking behavior and level of education were both related to adolescent smoking, whereas the same characteristics of mothers were not related to adolescent smoking. The observed differential relations between adolescent smoking and father and mother attributes is not consistent with earlier findings where both mother and father characteristics are typically predictive of adolescent smoking behavior (e.g., Fleming, Kim, Harachi, \& Catalano, 2002; Jackson \& Henrikson, 1997). One possible explanation for these discrepant findings may be that the current sample was rural and therefore may reflect a more traditional family structure than the families of the other research studies, which are typically more urban. A more traditional 
family structure for the current participants would lead mothers and fathers to have unique and clearly defined social roles in the family, which, by extension, would lead to differential parental effects. Fathers, relative to mothers in a more traditional family structure, may serve as more of a role model for their adolescent children regarding circumstances outside the immediate family and home whereas mothers may serve a more nurturing role and be less implicated in matters outside the home. In the present study, if fathers smoked, their adolescent children were more likely to smoke-as defined by the groups of the present study. Conversely, adolescents were less likely to smoke when their fathers had more education, which is consistent with previous research findings for both parents (e.g., Chassin, Presson, Sherman, \& Edwards, 1992). These two relations between father characteristics and adolescent smoking status appear to be independent in that father smoking and father education were not significantly correlated. Researchers have suggested that parental smoking constitutes a risk factor for adolescent smoking in that the parent is modeling a behavior as acceptable that the adolescent will eventually have to make a decision about, and that this effect can even be moderated if parents who smoke engage in "antismoking socialization" (Jackson \& Henrikson, 1997). For the present study, father smoking as a predictor of adolescent smoking is likely a modeling effect. Father education as a separate predictor may possibly be related to either better communication and clearer expectations about cigarette smoking by more educated fathers (i.e., antismoking socialization as described above) or to SES, with a higher level of father education being associated with a higher SES. Past research has shown SES to be a significant predictor of adolescent smoking, whereby lower SES is predictive of more adolescent cigarette smoking (e.g., Cleary et al., 1988; Scrinci, Robinson, Alfano, Zbikowski, \& Klesges, 2002). Unfortunately, for the present study, more direct estimates of participant SES are not available for further exploration of this latter speculation. 


\section{General Discussion}

In general, impulsivity and number of friends who smoke were examined as contributory factors to becoming or not becoming a regular smoker during adolescence. In one instance, it was found that PD differentiated between those who had recently tried smoking cigarettes and those who had never tried smoking-suggesting that impulsivity as measured by PD may play a role in adolescents initially trying cigarettes. Conversely, the measure of number of friends who smoke and the smoking behavior of one's best friend were less predictive of trying cigarettes (i.e., not significantly differing from past experimenters) and only marginally from never smokers (see Tables 1 \& 2) but did clearly

differentiate between never smokers and current smokers-suggesting that the smoking behavior of friends may not play as large a role in initially trying cigarettes but may be more related to long term patterns of smoking or non-smoking behavior.

The above pattern of results is different than what was originally hypothesized in that impulsivity was predicted to be highest for current smokers instead of triers, which would have matched the findings of previous DD research with adults (e.g., Bickel et al., 1999; Mitchell, 1999). One possible explanation for the present findings, in that both past experimenters and current smokers (who were all once triers) also were less (though not significantly) impulsive than triers, is that PD is not a stable trait-like characteristic for this population. Under this assumption, during periods of greater impulsivity, trying cigarettes may be more likely. Or, alternatively, some aspect of trying cigarettes may lead to a period of greater impulsivity, which also would match the present findings. Some research does suggest that DD in humans, which in the present study was correlated with PD, is not stable over time, with $k$ values for an individual fluctuating substantially across assessments done over an eight-week period (Critchfield, 2001). Other research has demonstrated variability in $k$ values as a function of induced mood, through instruction to think about either "happy" or "sad" memories 
and to listen to either "happy" or "sad" music (Beck \& Watts, 2001). That DD has been shown to be a variable dimension of human behavior lends plausibility to speculations that intra-individual variability in PD is related to trying cigarettes during adolescence.

Another possibility, though not researched, is that a third variable such as stress may lead individuals to try cigarettes and also to become more impulsive as determined by PD. Related to stress, some animal research has shown a significant positive relation between level of serum corticosterone in rats (which reliably elevates under conditions of stress) and task measures of DD (J.B. Richards, personal communication, September 13, 2001). Some other research also exists to suggest a link between stress and increases in certain behaviors associated with impulsivity. For example, elevated stress levels have been associated with increased cigarette smoking (Parrott, 1995), and alcohol abuse (Gorman, 1994), both of which, as already described, are related to greater DD. In this example, stress could directly lead an adolescent to try smoking, or it may lead to greater impulsivity, which then, in turn, may in part lead the adolescent to try cigarettes.

Despite the uncertainty of either possible explanation described above, or with other undiscussed explanations, it would still seem from the present findings that PD may play a larger role in the initiation of smoking than was originally hypothesized. This finding was also unexpected in that PD was related to smoking in adolescents, whereas in research with adults, PD has not been found to be related to cigarette smoking (Mitchell, 1999). Future longitudinal research could be oriented towards delineating more specifically the role of PD in adolescents trying cigarettes. Such research should emphasize the temporal stability of PD and factors that may lead to increases in PD. Relatedly, such research should also work to identify more broadly defined behavior changes (e.g., trying cigarettes, trying other drugs, or engaging in more risk-taking behavior) that accompany changes in PD. By extension, the relative roles of PD versus environmental conditions that could lead to increases 
in PD (e.g., home stress) in "causing" any accompanying behavior changes (e.g., trying cigarettes) should be examined. From such a research approach, novel combinations of both environmental and person variables may be discovered that lead an adolescent to be more likely to try smoking.

Another inconsistency in the present findings compared to research with adults is that PD was more predictive of smoking than DD, which has been the reverse pattern in adults (e.g., Mitchell, 1999). A possible explanation for this inconsistency might relate to developmental differences in time perception. It stands to reason that an individual's perception of time be related to his or her cumulative experience with time. For example, having to wait a year for something of value must be perceived differently by a 5 -year-old child than by a 40 -year-old adult. A year makes up a much larger percentage of the 5-year-old's total experience with time (20\%) than it does for the 40 -year-old (2.5\%). Therefore, one year constitutes a much larger time unit relative to the frame of reference for a child than for an adult. By extension, it is likely that a year would be perceived as much longer by a 5 -yearold than by a 40-year-old. Such potential age-dependent differences in perception of time may account for some inconsistencies in DD across different age groups. Again, for the present study, participants were between 14 and 16 years of age, whereas adult findings have typically been found with participants around 30 years of age (e.g., Bickel et al., 1999). Undoubtably, the age disparity between the participants of the present study and the older participants of other impulsivity-related smoking research has led to some inconsistencies between these studies, especially as related to time perception.

For participants who perceive delays as longer (as younger participants would), rates of discounting should be either (a) steeper than for participants who do not perceive delays to be as long or (b) steeper for shorter delays (i.e., logical discounting) and then less steep for longer delays in that the participant essentially stops discounting beyond what is a comprehensible delay length for him or her. Put another way, longer delays may lose meaning for younger participants in that the younger 
participants do not fully differentiate between such delays (e.g., 180 versus 365 days-they are both just very long) and therefore do not discount differently between the longer delays. In a study by Green, Fry, and Myerson (1994) comparing age differences in DD between older adults, young adults, and children, the children (between 12 and 13 years of age) exhibited this pattern of DD curtailment with the longer delays. The general pattern across all the groups was that younger participants discounted more steeply than older participants. This pattern held true across all groups and delays except between the children and young adults at the longest delays, where the children actually discounted less than the young adults. The younger participants do appear to have stopped discounting at the longer delays relative to the young adults. Such an overriding tendency for younger participants at longer delays would likely lead to a reduction in within-group and between-group variability, which would neutralize the effects of other variables (e.g., smoking group status) and therefore, by extension, reduce chances of finding between-group differences within this age period. For the present study, attenuated DD at the longer delays is likely responsible for the lack of predictive utility for this normally predictive measure in older participants.

An interesting and counterintuitive research question arises from such a possibility: Do younger participants discount more steeply for relatively short delays than they do for considerably longer delays? For example, it is possible that participants of this age group who would be asked DD questions with delays between 1 day and roughly 1 1/2 months (e.g., delays of 1 day, 5 days, 10 days, 20 days, and 40 days) may have higher $k$ values than similar participants asked questions with delays between 1 day and roughly 2 years (e.g., delays of 1 day, 75 days, 150 days, 300 days, and 600 days).

Such a finding would not reflect logical DD but would lend support to the hypothesis that early to middle adolescent participants perceive longer delays differently than adult participants, and therefore the DD procedure would require modifications or younger participants to compensate for 
their lack of differentiation between the longer delays. For any future research involving DD with adolescents, pilot studies with longer and shorter delays should be conducted to determine the series of delay intervals that produces the highest $\mathrm{R}^{2}$ values. Future research with modified, age appropriate delay intervals may yield smoking group differences in DD not found in the present study.

Alternatively, perceptions of probability are not as susceptible to cumulative experience effects in that there is no age-related changing frame of reference for probability. By the age of 14 , most of the participants should have had exposure to probabilistic circumstances and may have had a more adult-like perception of probability than they did of time. Therefore, it is possible that PD was a more accurate measure of discounting for this sample than DD was (as reflected by the higher $\mathrm{R}^{2}$ values for PD than for DD-see Figures 2 and 3), which could, in part, also account for the inconsistency between the findings of the present study and studies of adults. Unfortunately, the study by Green et al. (1994) is the only published developmental study of discounting, which was only with delay and not probability.

With respect to friends, the number of friends who smoke was most predictive of stable patterns of either regular smoking or never trying smoking. These findings are consistent with some past research (e.g., Ary \& Biglan, 1988; Chassin, Presson, Sherman, Montello, \& McGrew, 1986), but they are inconsistent with other findings (e.g., Chassin, Presson, Sherman, Corty, \& Olshavsky, 1984; Flay et al., 1994). From Table 2 it can be seen that even best friend smoking behavior was by far most related to those participants who were smoking regularly, as seen in the bottom-most right cell of Table 2. As already suggested, this pattern in these data is less consistent with friendships playing a significant role in adolescents trying cigarettes and is more consistent with friendships perhaps serving to "crystalize" either a preference to smoke regularly or to not try smoking at all. Research on adolescent friendships has shown that during adolescence friends are more similar than during earlier 
developmental periods (e.g., early childhood, middle childhood) with respect to attributes like drug or alcohol use or attitudes about school (e.g., see Rubin et al., 1999). Results from the present study suggest that adolescents perhaps try smoking or do not try smoking for any number of reasons, but then gravitate towards peer friends who are similar to them in ways that may serve to further establish either a pattern of long term smoking or continued abstinence from even trying cigarettes.

Related future research might compare current regular smokers and past regular smokers. From the above discussion, one would predict that current regular smokers would have a high number of friends who smoke, as found in the present study, and that past regular smokers would have significantly fewer friends who smoke. Such a pattern would lend support to the notion that adolescents gravitate to peer friends who match their own values with respect to smoking. To examine this possibility more closely, longitudinal research could track adolescents who have recently quit smoking (perhaps through a smoking cessation program) to determine if a redistribution of the number of friends who smoke does occur following cessation. To answer this question, more specific questions would need to be asked about exactly who the participant's friends are over time instead of just questions about how many of their friends smoke.

The present findings, if corroborated by future research, have implications for intervention efforts to reduce smoking during adolescence. If heightened PD is related to adolescents initially trying cigarettes, then preventive types of intervention research should target identifying when and how PD increases. Resultant intervention efforts would no doubt include identifying populations at-risk for increased PD and then orient more intensive interventions towards persuading these adolescents away from trying cigarettes and towards other types of less destructive behaviors. For example, if research were to show that elevated stress does lead to increased PD, which then leads an adolescent to be 
more likely to try smoking, then preventive interventions should offer stress-coping alternatives to trying cigarettes-like exercise or new hobbies.

If, however, stress is occurring under circumstances that cannot be changed in a way to reduce stress, then interventions still may be able to target the specific choice options in ways to increase the subjective value of not smoking relative to the value of smoking. A program might, for example, reward not smoking with monetary incentives (thus increasing the subjective value of not smoking) and punish smoking with the loss of already accumulated rewards (thus decreasing the subjective value of smoking). This might be done by having at-risk adolescents agree to participate in an antismoking program where they have the potential to earn some sum of money (e.g., \$100). For an extended program, for example, participants would be given $\$ 30$ up front and be told that they would be given the remaining money (\$70) in even increments during "check-in" or educational sessions once it had been determined that they had not smoked since the previous check-in time (to be determined by a breath test). However, if it was determined that a participant had smoked, then he or she would not receive that increment of money and would also be required to return $\$ 10$ of the $\$ 30$ he or she originally received. Such an approach would manipulate the values of smoking versus not smoking in a manner as to increase the likelihood that the adolescents would not smoke during the program. The present results would suggest, though, that preventive efforts oriented towards peer pressure, or reducing the effects of peer pressure or exposure to cigarettes through peer friends, may be targeting the wrong contributory factors for this stage of adolescent smoking.

Alternatively, smoking cessation interventions might be more effective when they do emphasize peer influence relative to person characteristics such as degree of PD. As seen in Table 2, the vast majority of best friends for current smokers also smoked. Efforts to encourage or to help these adolescents to stop smoking cigarettes cannot afford to ignore the possible impact of these 
friends who smoke. Such interventions might either strive to reduce the influence of perceived peer pressure to smoke or encourage the development of new friendships that do not involve smoking. Or, smoking cessation programs might encourage participants through the use of incentives to invite their friends who smoke to the cessation program. Either way, friends who smoke appears to be a factor that may be important in efforts to help adolescents stop smoking once they have become regular smokers.

Though many of the findings of the present study must be accepted tentatively, these results do suggest a pattern of differential influence across the different stages of adolescent smoking. The present findings should encourage future research to examine more closely different factors that may contribute to the initiation or continuation of smoking in adolescents. 


\section{References}

Ainslie, G. (1975). Specious reward: A behavioral theory of impulsiveness and impulse control. Psychological Bulletin, 82, 463-496.

Ary, D., \& Biglan, A. (1988). Longitudinal changes in adolescent cigarette smoking behavior: Onset and cessation. Journal of Behavioral Medicine, 11, 361-382.

Ashton, H., \& Stepney, R. (1982). Smoking: Psychology and pharmacology. London: Tavistock.

Beck, R. C., \& Watts, A. (2001). Personality variables related to temporal discounting. Poster presented at the Southeastern Psychological Association, Atlanta, GA.

Berndt, T. J. (1982). The features and effects of friendships in early adolescence. Child Development, 53, 1447-1460.

Berndt, T. J. (1992). Friendships and friends' influence in adolescence. Current Directions in Psychological Science, 1, 156-159.

Bickel, W., Odum, A., \& Madden, G. (1999). Impulsivity and cigarette smoking: Delay discounting in current, never, and ex-smokers. Psychopharmacology, 146, 447-454.

Conrad, K., Flay, B., \& Hill, D. (1992). Why children start smoking cigarettes: Predictors of onset. British Journal of Addiction, 87, 1711-1724.

Charlton, A. (1984). The Brigantia smoking survey: A general review. Public education about cancer. (UICC Technical Report Series, Vol. 77, pp. 92-102). Geneva, Union International Contre le Cancer.

Chassin, L., Presson, C., \& Sherman, S. (1984). Cognitive and social influence factors in adolescent smoking cessation. Addictive Behavior, 9, 383-390. 
Chassin, L., Presson, C., Sherman, S., Corty, E., \& Olshavsky, R. (1984). Predicting the onset of cigarette smoking in adolescents: A longitudinal study. Journal of Applied Social Psychology, 14, $224-243$.

Chassin, L., Presson, C., Sherman, S., Montello, D., \& McGrew, J. (1986). Changes in peer and parent influence during adolescence: Longitudinal versus cross sectional perspectives on smoking initiation. Developmental Psychology, 22, 327-334.

Chassin, L., Presson, C., Sherman, S., Edwards, D. (1992). Parental educational attainment and dolescent cigarette smoking. Journal of Substance Abuse, 4, 219-234.

Cherry, N. \& Kiernan, K. (1976). Personality scores and smoking behavior. British Journal of Preventive and Social Medicine, 30, 123-131.

Cleary, P. D., Hitchcock, J., Semmer, N., Flinchbaugh, L. et al. (1988). Adolescent smoking: Research and health policy. Milbank Quarterly, 66, 137-171.

Crean, J. P., de Wit, H., \& Richards, J. B. (2000). Reward discounting as a measure of impulsive behavior in a psychiatric outpatient population. Experimental Clinical Psychopharmacology, 8, 155162.

Critchfield, T. S., (2001).Temporal discounting of gains and losses: Reliability in multiple assessments over 8 weeks. Poster presented at the Association for Behavior Analysis Convention, New Orleans, LA.

Diaz, R., \& Berndt, T. (1982). Children's knowledge of a best friend: Fact of fancy. Developmental Psychology, 18, 787-794.

Engels, R., Knibbe, R., de Vries, H., \& Drop, M. (1998). Antecedents of smoking cessation among adolescents: Who is motivated to change? Preventive Medicine, 27, 348-357.

Erikson, E. (1968). Identity: Youth and crisis. New York: Norton. 
Ershler, J., Leventhal, H., Fleming, R., \& Glynn, K. (1989). The quitting experience for smokers in sixth through twelfth grades. Addictive Behavior, 14, 365-378.Evenden, J. (1999). Varieties of impulsivity. Psychopharmacology, 146, 348-361.

Fiore, M. C. (1992). Trends in cigarette smoking in the United States: the epidemiology of tobacco use. Medical Clinics of North America, 76, 289-303.

Flay, B., D’ Avernas, J., Best, J., Kersell, M., \& Ryan, K. (1983). Cigarette smoking: Why young people do it and ways of preventing it. In P. McGrath \& P. Firestone (Eds.), Pediatric and adolescent behavioral medicine: Issues in treatment (pp. 132-183). New York: Springer.

Flay, B., Hu., F., Siddiqui, O., Day L., Hedeker, D., Petraitis, J., Richardson, J., \& Sussman, S. (1994). Differential influence of parental smoking and friends' smoking on adolescent initiation and escalation of smoking. Journal of Health and Social Behavior, 35, 248-265.

Fleming, C., Kim, H., Harachi, T., \& Catalano, R. (2002). Family processes for children in early elementary school as predictors of smoking initiation. Journal of Adolescent Health, 30, 184-189.

Forgays, D. G. (1986). Personality characteristics and self-abusive behavior. In S. I. Szara (Ed.), Neurobiology of Behavioral Control in Drug Abuse (NIDA Research Monograph 74). Washington, D. C.: NIDA.

Glynn, T. J., Anderson, M., Schwartz, L. (1991). Tobacco-use reduction among high risk youth: Recommendations of a National Cancer Institute expert advisory panel, Preventive Medicine, 20, $279-291$.

Gorman, D. M. (1994). Alcohol misuse and the predisposing environment. British Medical Bulletin: 36-49

Green, L., Fry, A., \& Myerson, J. (1994). Discounting of delayed rewards: A life-span comparison. Psychological Science, 5, 33-36. 
Gromly, A. (1997). Lifespan human development. Fort Worth, TX: Harcourt Brace College Publishers.

Hartup, W. (1983). Peer relations. In E. Hetherington (Ed.), Handbook of child psychology: Vol. 4. Socialization, personality, and social development (4 $4^{\text {th }}$ ed., pp. 103-196). New York: Wiley.

Hartup, W., (1996). The company they keep: Friendships and their developmental significance. Child Development, 67, 1-13.

Hover, S., \& Gaffney L. (1988). Factors associated with smoking behavior in adolescent girls. Addictive Behaviors, 13, 139-145.

Ikard, F., Green, D., \& Horn, D. (1969). A scale to differentiate between types of smoking as related to management of affect. International Journal of the Addictions, 4, 649-659.

Jackson, C., \& Henriksen, L. (1997). Do as I say: Parent smoking, antismoking socialization, and smoking onset among children. Addictive Behaviors, 22, 107-114.

Kagel, J., Green, L., \& Caraco, T. (1986). When foragers discount the future: Constraint or adoption? Animal Behavior, 34, 271-283.

Kirby K.N., \& Marakovic, N. N. (1996) Delay-discounting probabilistic rewards: Rates decrease as amounts increase. Psychonomic Bulletin \& Review, 3, 100-104.

Koda, V. (1999). Gender differences in the neuropsychology of childhood aggression. Dissertation Abstracts International: Section B: The Sciences and Engineering, 60, 388.

Krohn, M., Massey, J., Skinner, W., \& Lauer, R. (1983). Social bonding theory and adolescent cigarette smoking: A longitudinal analysis. Journal of Health and Social Behavior, 24, 337-349.

Kupersmidt, J., DeRosier, M., \& Patterson, C. (1995). Similarity as the basis for children's friendships: The roles of sociometric status, aggressive and withdrawn behavior, academic achievement and demographic characteristics. Journal of Social and Personal Relationships, 12, 439-452. 
Leventhal, H., \& Cleary, P. (1980). The smoking problem: A review of the research and theory in behavioral risk modification. Psychological Bulletin, 88, 370-405.

Logue, A., (1988). Research on self-control: An integrating framework. Behavioral and Brain Science, 11, 665-679.

Logue, A., \& Anderson, Y. (2001). Higher education administrators: when the future does not make a difference. Psychological Science, 12, 276-281.

Mayhew, K., Flay, B., \& Mott, J. (2000). Stages in the development of adolescent smoking. Drug and Alcohol Dependence, 59, 61-81.

Mazur, J. E. (1987). An adjusting procedure for studying delayed reinforcement. In M. L. Commons, J. E. Mazur, J. A. Nevin, \& H. Rachlin (Eds.), Quantitative analysis of behavior: Vol 5. The effects of delay and intervening events on reinforcement value (pp. 55-73). Hillsdale, NJ: Erlbaum.

McMahon, Jason, \& Salina (1994). Stress, coping, and appraisal in a smoking cessation intervention. Anxiety, Stress, and Coping, 7, 161-171.

Mischel, W. (1999). Personality coherence and dispositions in a cognitive-affective personality system (CAPS) approach. In D. Cervone \& Y. Shoda (Eds.), The coherence of personality: Social-cognitive bases of consistency, variability, and organization (pp. 37-60). New York, NY: Gilford.

Mitchell, S. (1999). Measures of impulsivity in cigarette smokers and non-smokers. Psychopharmacology, $146,455-464$.

Monterosso, J., Ainslie, G. (1999). Beyond discounting: Possible experimental models of impulse control. Psychopharmacology, 146, 339-347.

Origin 6.0 [Computer software]. (1999). Northampton, MA: Microcal Software Inc.

Palmer, A. (1970). Some variables contributing to the onset of cigarette smoking among junior high school students. Social Science and Medicine, 4, 359-366. 
Parrott, A. C. (1995). Stress modulation over the day in cigarette smokers. Addiction, 90, 233-244.

Rachlin, H. (1989). Judgement, decision, and choice: A cognitive/ behavioral synthesis. New York: Freeman.

Rachlin, H. (1995). Self-control: Beyond commitment. Behavioral and Brain Science, 18, 109-159.

Rachlin, H., \& Green, L. (1972). Commitment, choice and self-control. Journal of the Experimental Analysis of Behavior, 17, 15-22.

Rachlin, H., Raineri, A., \& Cross, D. (1991). Subjective probability and delay. Journal of the Experimental Analysis of Behavior, 55, 233-244.

Reynolds, B. (2002). Personality development. In N. Salkind (Ed.), Child Development: Vol. 1. Macmillan Psychology Reference Series (pp. 300-305). New York: Gale Group.

Reynolds, B., \& Karraker, K. (in press). A Big Five model of disposition and situation interaction: Why a "helpful" person may not always behave helpfully. New Ideas in Psychology.

Richards, J.B., Mitchell, S., de Wit, H., \& Seiden, L. (1997). Determination of discount functions in rats with an adjusting-amount procedure. Journal of the Experimental Analysis of Behavior, 67, 353-366.

Richards, J.B., Zhang, L., Mitchell, S., \& de Wit, H. (1999). Delay and probability discounting in a model of impulsive behavior: Effect of alcohol. Journal of the Experimental Analysis of Behavior, 71, 121-143.

Rose, J., Chassin, L., Presson, C., \& Sherman, S. (1996). Prospective predictors of quit attempts and smoking cessation in young adults. Health Psychology, 15, 261-268.

Rubin, K., Coplan, R., Nelson, L., \& Sagace-Seguin (1999). Peer relationships in childhood. In M. Bornstein \& M. Lamb (Eds.), Developmental psychology: An advanced text (pp. 451-501). New Jersey, NJ: Erlbaum. 
Salber, E., Freeman, H., \& Abelin, T. (1968). Needed research on smoking: Lessons from the Newton Study. In E. Borgatta \& R. Evans (Eds.), Smoking, health, and behavior (pp. 182-203). Chicago: Aldine.

Savin-Williams, R., \& Berndt, T. (1990). Friendship and peer relations. In S. Feldman \& Elliott, G. (Eds.), At the threshold: The developing adolescent (pp. 277-307). Cambridge, MA: Harvard University Press.

Scarinici, I. C., Robinson, L., Alfano, C. M., Zbikowski, S. M., \& Klesges, R. (2002). The relationship between socioeconomic status, ethnicity, and cigarette smoking in urban adolescents. Preventive Medicine: An International Journal Devoted to Practice and Theory, 34, 171-178.

Sieber, M. \& Angst, J. (1990). Alcohol, tobacco and cannabis: 12 year longitudinal associations with antecedent social context and personality. Drug and Alcohol Dependence, 25, 281-292.

Singleton, L., \& Asher, S. (1979). Racial integration and children's peer preferences: An investigation of developmental and cohort differences. Child Development, 50, 936-941.

Tompkins, N., Dino, G., Zedosky, L., Harman, M., \& Shaler, G. (1999). A collaborative partnership to enhance school-based tobacco control policies in West Virginia. American Journal of Preventive Medicine, 16, 29-34.

Tompson, R. (1999). The individual child: temperament, emotion, self, and personality. In M. Bornstein \& M. Lamb (Eds.), Developmental psychology: An advanced text (pp. 377-409). New Jersey, NJ: Erlbaum.

Van Roosmalen, E., \& McDaniel, S. (1989). Peer group influence as a factor in smoking behavior of adolescents. Adolescence, 24, 801-816.

Vuchinich, R., \& Simpson, C. (1998). Hyperbolic temporal discounting in social drinkers and problem drinkers. Experimental Clinical Psychopharmacology, 6, 292-305. 
Waldeck, T., \& Miller, L. (1997). Gender and impulsivity differences in licit substance use. Journal of Substance Abuse, 9, 269-275.

West, P., \& Michell, L. (1999). Smoking and peer influence. In A. Goreczny \& M. Hersen (Eds.), Handbook of pediatric and adolescent health psychology (pp. 179-202). Boston: Allyn and Bacon.

West, P., Sweeting, H., \& Ecob, R. (1999). Family and friends' influences on the uptake of regular smoking from mid-adolescence to early adulthood. Addiction, 94, 1397-1411 .

White, H. R., Pandina, R. J., \& Chen, P. H. (2002). Developmental trajectories of cigarette use from early adolescence into young adulthood. Drug and Alcohol Dependence, 65, 167-178.

Wills, T. A., \& Cleary, S. D. (1997). The validity of self-reports of smoking: Analysis by race/ethnicity in a school sample of urban adolescents. American Journal of Public Health, 87, 56-61.

Zuckerman, M., Ball, S., \& Black, J. (1990). Influences of sensation seeking, gender, risk appraisal, and situational motivation on smoking. Addictive Behavior, 15, 209-220. 


\title{
Appendix A
}

\section{Letter to Parents/Guardians of Potential Participants}

\author{
Dear Parents/Guardians:
}

As part of a research project through the Department of Psychology at West Virginia University, we are conducting a study to explore predictors of teenage cigarette smoking, and we would like to invite your child to participatej. we are interested in how certain personality characteristics as well as certain social/friendship characteristics relate to different patterns of teenage cigarette smoking. For this study, we need teens with different smoking experiences: from those who have never even tried cigarette smoking or smokeless tobacco to those who currently smoke at least one cigarette a week.

Should you allow your child to participate in this study, he or she will either particiapte at school or be asked to come to the Developmental Research Suite in Oglebay Hall at West Virginia University. It will take about 30 minutes to complete and will take place during one visit. Your child will performe a computerized choice-like procedure, and he or she will earn between $\$ \mathbf{1 0 . 0 0}$ and $\mathbf{\$ 2 0 . 0 0}$, depending on choice preferences during the computerized procedure. Your child will also be asked to complete a short questionnaire, including questions about cigarette smoking among family and freinds.

Be assured that all information we collect from your child will be treated confidentially. Your child will have the right to stop participation in this study at any time. Upon completion, you child will be paid the money earned, or arrangements will be made so that your child will receive payment through the mail. You may also receive the results of the study once it is completed, if you wish.

If you and your child are interested in getting more information about this study, please contact one of the persons listed below. If yoiu leave a message, your call will be returned as soon as possible.

We look forward to speaking with you and would very much appreciate your help in conducting this research project. Thank you for your time and consideration.

Sincerely,

Brady Reynolds, M.A.

Doctoral Student

293-2001, ext 869
Katherine Karraker, Ph.D.

Associate Professor

293-2001, ext 625 


\section{Appendix B}

$P A R E N T A L / G U A R D I A N$

\section{O N S E N T F OR M}

Title: Person and Social Characteristics

Related to Adolescent Cigarette Smoking

Version Date: 01/08/2002

Introduction. I, , have been asked to allow my child, , to participate in this study. Brady Reynolds, who is conducting this research to fulfill the requirements for a doctoral dissertation in Life Span Developmental Psychology in the Department of Psychology at West Virginia University, has given me information regarding the study and has been available to answer any questions I have had.

Purpose of the Study. The primary purpose of this study is to examine the relation between certain personality characteristics and certain social variables with different patterns or stages of adolescent cigarette smoking. If personality and/or social characteristics are found to be predictive of an adolescent's experimentation with cigarette smoking or continuing on to become a regular smoker, such information could be useful in developing anti smoking and smoking cessation programs.

Description of Procedures. Approximately 80 adolescents will participate in this study. I understand that this research study involves data collection at one time only. Data collection for this study will be done at the Department of Psychology in the Developmental Research Suite and at recruitment sites where appropriate (e.g., high schools and community centers). I also understand that my child's participation will take approximately $1 / 2$ hour. During participation, my child will be asked to answer some questions on a computer about his or her preference for differing amounts of money to be received at different times. My child's answers to these questions will determine, in part, how much money he or she receives for participating in this study. This money will be in addition to the $\$ 10.00$ all participants receive for participating in this study. After answering the computerized questions, my child will complete a short questionnaire about school, family, and friends. I have been given the opportunity to examine the materials used for this study and I know that my child does not have to answer all of the questions.

Initials Date

Page 1 of 3 
Person and Social Characteristics

Related to Adolescent Cigarette Smoking

Risks and Discomforts. There are no known or expected risks from participating in this study, except the mild frustration of completing a questionnaire.

Benefits. I understand that this study is not expected to be of direct benefit to my child. However, I also understand that the knowledge gained may be of benefit to others and help contribute to a scientific understanding of cigarette smoking in adolescents.

Financial Considerations: I understand that my child will receive $\$ 10.00$ for participating in this study. I also understand that my child will receive between $\$ 0.25$ and $\$ 10.00$ in addition to the $\$ 10.00$ all participants receive for their participation. The amount of additional money and when my child receives this additional money will be determined by his or her choices on the computerized task. One of the choices on the computerized task will be selected at random, and my child will receive the amount of money at the time specified by the selected choice.

Alternative. I understand that my child does not have to participate in this study.

Contact Persons. For more information about this research, I can contact Brady Reynolds at 304/293-2001 x869 or his supervisor, Dr. Katherine Karraker, at 304/293-2001 x625. For information on my rights and the rights of my child as a research participant, I may contact the Executive Secretary of the Institutional Review Board of West Virginia University at 304/2937073.

Confidentiality. I understand that any information obtained as a result of my child's participation in this research will be kept as confidential as legally possible. I understand that these research records, just like hospital records, may be subpoenaed by court order or may be inspected by federal regulatory authorities. Neither my nor my child's name or any information from which we might be identified will be published without my consent.

Initials Date

Page 2 of 3 
Person and Social Characteristics

Related to Adolescent Cigarette Smoking

Voluntary participation. Participation in this study is completely voluntary. I understand that I may withdraw my child from this study at any time. Refusal to participate or withdrawal will involve no penalty or loss of benefits to me or my child. I have been given the opportunity to ask questions about the research, and I have received answers concerning areas I did not understand.

Upon signing this form, I will receive a copy.

I willingly consent to my child's participation in this research.

Signature of Parent or Guardian

Date

Time

Signature of Investigator or

Date

Time

Investigator's Representative

Version Date: 01/08/2002

Page 3 of 3 


\section{A S S E N T F O R M}

Title: Person and Social Characteristics

Related to Adolescent Cigarette Smoking

Version Date: 01/08/2002

Introduction. I, , have been invited to participate in this research study that has been explained to me by

Purposes of the Study. The primary purpose of this study is to examine the relation between certain personality characteristics and certain social variables and different patterns of adolescent cigarette smoking. If personality and/or social characteristics are found to be predictive of an adolescent's experimentation with cigarette smoking or continuing on to become a regular smokier, such information could be useful in developing anti smoking and smoking cessation programs.

Procedures. Approximately 80 adolescents will participate in this study. I understand that this research study involves data collection at one time only. I also understand that my participation will take approximately $1 / 2$ hour. During participation, I will be asked to answer some questions on a computer about my preference for differing amounts of money to be received at different times. My answers to these questions will determine, in part, how much money I receive for participating in this study. One of my answers to these questions will be selected at random, and I will receive the amount of money at the time specified by the selected question. This money will be in addition to the $\$ 10.00$ everyone receives for participating in this study. After answering the computerized questions, I will complete a short questionnaire about school, family, and friends. I have been given the opportunity to examine all of the materials and instruments described above.

Risks and Discomforts. There are no known or expected risks from participating in this study, except the mild frustration of completing a questionnaire.

Initials Date

Page 1 of 2 
Person and Social Characteristics

Related to Adolescent Cigarette Smoking

Benefits. I understand that this study is not expected to be of direct benefit to me. However, I also understand that the knowledge gained may be of benefit to others and help contribute to a scientific understanding of cigarette smoking among adolescents.

Financial Considerations. I understand that I will receive $\$ 10.00$ for participating in this study. I also understand that $I$ will receive between $\$ 0.25$ and $\$ 10.00$ in addition to the $\$ 10.00$ all participants receive. The amount of money and when I receive this additional money will be determined by my choices on the computerized task.

Voluntary participation. I have been told that I do not have to participate do this. No one will be mad at me if I refuse to do this, or if I decide to quit. I have been allowed to ask questions about the research and all of my questions have been answered.

Upon signing this form, I will receive a copy.

I willingly agree to be in this research.

Signature of Participant

Date

Time

Signature of Investigator or

Date

Time

Investigator's Representative

Version Date: 01/08/2002

Page 2 of 2 
Appendix C

Demographic Questions $\quad$ Participant \#

NOTE: In the questions below, other caregiver refers to any adult in your life who you presently live with a substantial amount of time.

1. What is your age:

2. Sex: Male Female

3. Grade in School:

4. Race: Black White Asian Hispanic Native American Other

5. How many siblings (brothers or sisters) do you have: (circle one)

$\begin{array}{lllllll}1 & 2 & 3 & 4 & 5 & \text { Other }\end{array}$

6. If you have siblings, what are their ages:

7. What caregivers do you currently live with most of the time:(circle as many as apply)

Mother Father Stepmother Stepfather Grandparents Other

8. What is the highest level of education or highest degree attained by your:

(For example: some high school, high school degree, some college, four-year college degree, some graduate school, graduate degree)

Mother

Father

Other caregiver

9. Specifically, what type of work does your mother, father, or other caregiver do? (For example: construction worker, teacher, homemaker, doctor)

Mother

Father

Other caregiver 
Demographic Questions Participant \#

10. Estimate your household income (how much money your household makes annually):

(circle one)

$\$ 10,000-\$ 20,000 \quad \$ 21,000-\& 30,000 \quad \$ 31,000-\$ 40,000 \quad \$ 41,000-\$ 50,000$ Don't know Other:

11. What is the age of your:

1. Mother

2. Father

3. Other caregiver

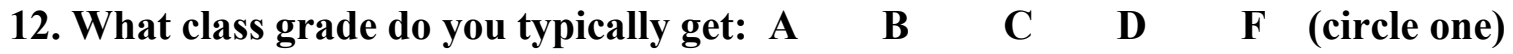

13. How many of your friends smoke cigarettes? (Please circle one of the options below)

None

Some

Half

Most

All

14. How many of your male friends smoke cigarettes?

(Please circle one of the options below)

None

Some

Half

Most

All

15. How many of your female friends smoke cigarettes? (Please circle one of the options below)
None
Some
Half
Most
All

16. If you have siblings, how many (from question 5) smoke cigarettes:

17. Does your mother smoke? (circle yes or no)

18. Does your father smoke? (circle yes or no)

19. Do any other caregivers smoke? (circle yes or no) 
20. Not counting siblings, parents or other caregivers, how many members of your family (aunts, uncles, grandparents) smoke cigarettes? (Please circle one of the options below)

None

Some

Half

Most

All

21. Does your closest or best friend smoke cigarettes? (circle one)

1

Has Never

Smoked
2

Just Recently

Tried Smoking
3

Tried Smoking in the

Past, but quit smoking
4

Smokes Regularly

Now

22. Do you currently use any form of smokeless tobacco (chewing tobacco or snuff)?

(circle one) Yes No

23. Do you currently smoke cigarettes or have you ever tried smoking cigarettes?

(circle one) Yes No

ANSWER QUESTIONS 24 \& 25 IF YOU SMOKE REGULARLY NOW

24. For how long have you smoked cigarettes?

25. On average, how many cigarettes do you smoke a week?

ANSWER QUESTIONS 26 \& 27 IF YOU HAVE ONLY TRIED SMOKING

26. How long ago was it that you tried smoking?

27. How many cigarettes have you tried? 


\section{Appendix D}

\section{Basic instructional script to be reviewed with participants}

1. Introduce yourself and everyone else that will be working with them....thank them up front for their participation.

\section{Stages of participation:}

a) First part you will do here in the computer lab

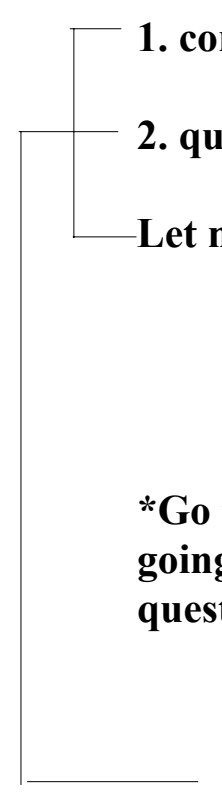
delays or with different chances. There are no right or wrong answers to these questions.... just pick which you would prefer.

*Go through some examples of questions and explain what they mean. Keep going through questions until you have had at least 1 DD question and 1 DG question.

Once you have finished the computer program, answer the questions on the questionnaire that is at your computer. If you have any questions about the questionnaire, raise your hand and one of us will help you. Once you have finished the questionnaire, raise your hand and one of us will give you a hall pass to go to Mrs. Connaway's room for the second stage of your participation-payment.

\section{b) Second stage of the study will be done in Mrs. Connaway's room}

The questions that you answer with the computer program are important because one of your answers to these questions will be selected at random and you will get what you chose. You will get $\$ 10.00$ just for participating in the study, but what you get beyond that will be determined by your randomly selected question. If in your randomly selected choice you chose delayed money, the money will be put in an envelope with your name and address on it, and it will be mailed to you after the specified delay. For example, if you chose $\$ 10.00$ in 180 days from now, then $\$ 10.00$ will be mailed to you in 180 days. Alternatively, if your selected answer is a "chance" question, then you will draw poker chips from a bag to see if you get the money or not. For example, if your selected answer is that you have a $25 \%$ chance of getting $\$ 10.00$, then three red poker chips and one blue poker chip will be put in a bag for you to draw from. If you draw the one blue poker chip you will get the \$10.00, but if you draw one of the three red poker chips you will not get the money.

Any Questions? 